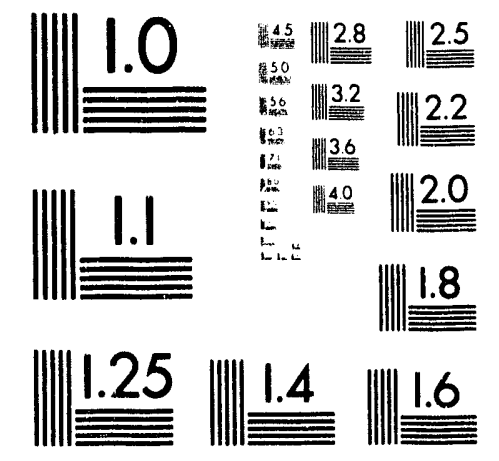



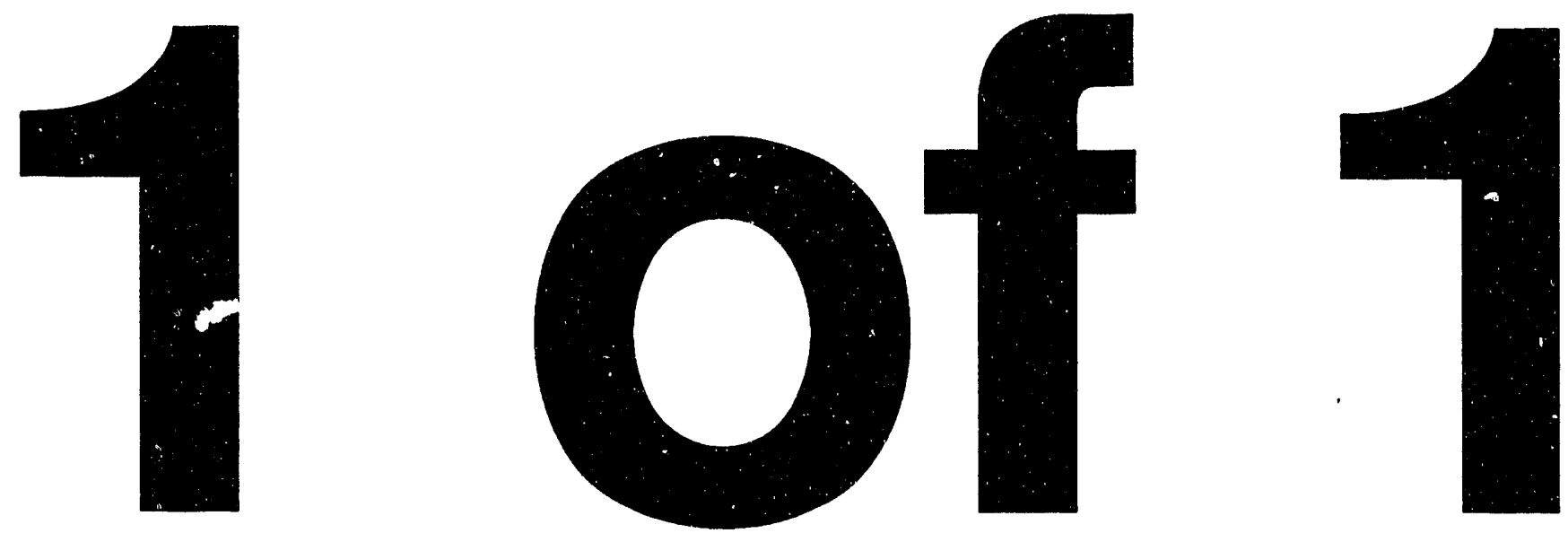


\title{
POLYMERS FOR SUBTERRANEAN CONTAINMENT BARRIERS FOR UNDERGROUND STORAGE TANKS (USTS) \\ Letter Report on FY 1992 Activities
}

\author{
John H. Heiser \\ Peter Colombo \\ James Clinton
}

December 1992

\author{
BROOKHAVEN NATIONAL LABORATORY \\ ASSOCIATED UNIVERSITIES, INC. \\ UPTON, NEW YORK 11973
}

UNITED STATES DEPARTMENT OF ENERGY

CONTRACT NO. DE-ACO2-76CH0O016

TTP NO.: CH321203

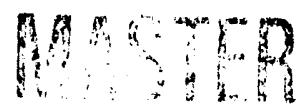


1. INTRODUCTION $\ldots \ldots \ldots \ldots \ldots \ldots \ldots \ldots \ldots \ldots \ldots \ldots \ldots \ldots \ldots \ldots$

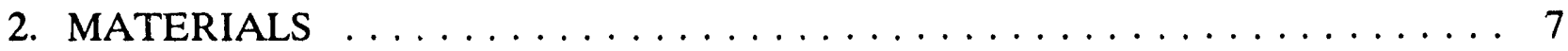

2.1 Methacrylates ....................... 8

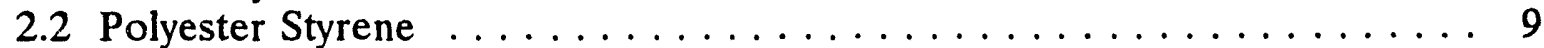

2.3 Vinylester Styrene $\ldots \ldots \ldots \ldots \ldots \ldots \ldots \ldots \ldots$

2.4 Furfuryl Alcohol $\ldots \ldots \ldots \ldots \ldots \ldots \ldots \ldots \ldots \ldots \ldots$

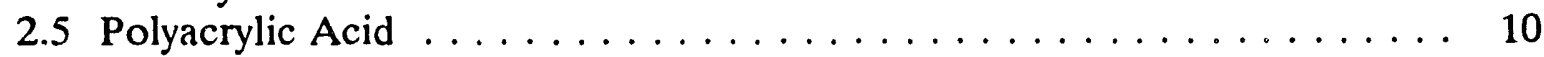

2.6 Modified Sulfur Cement $\ldots \ldots \ldots \ldots \ldots \ldots \ldots \ldots \ldots \ldots$

3. FORMULATIONS $\ldots \ldots \ldots \ldots \ldots \ldots \ldots \ldots \ldots \ldots \ldots \ldots \ldots \ldots \ldots$

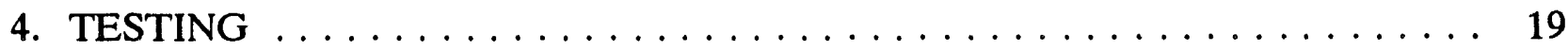

4.1 90-Day Water Immersion Test $\ldots \ldots \ldots \ldots \ldots \ldots \ldots \ldots \ldots$

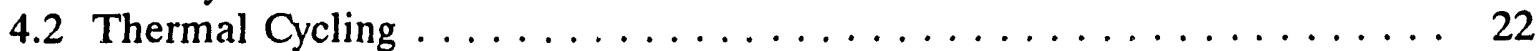

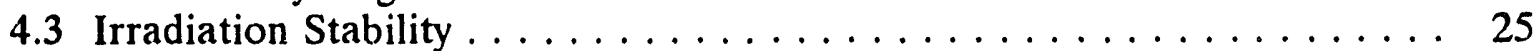

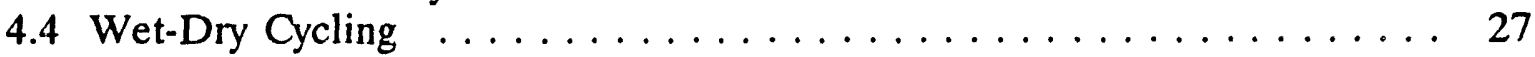

4.5 Hot Nitrate Brine Immersion $\ldots \ldots \ldots \ldots \ldots \ldots \ldots \ldots \ldots \ldots$

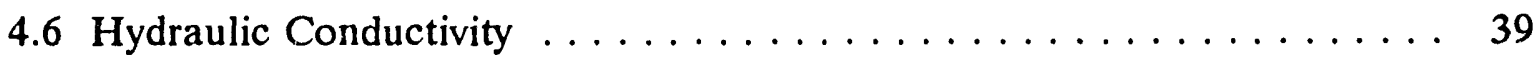

5. CONCLUSIONS $\ldots \ldots \ldots \ldots \ldots \ldots \ldots \ldots \ldots \ldots \ldots \ldots \ldots \ldots \ldots \ldots \ldots$

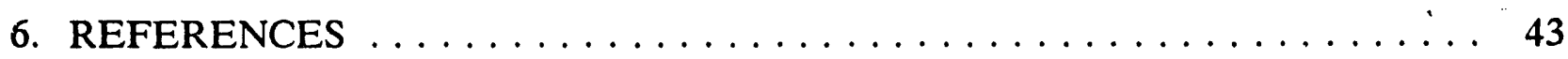




\section{LIST OF FIGURES}

Page

Figure 1 Schematic of proposed confinement barrier for underground storage tanks. 2

Figure 2 Placement of a confinement barrier using jet grouting. $\ldots \ldots \ldots \ldots$

Figure 3 Placement of a confinement barrier using permeation grouting. . . . . . 4

Figure 4 Vinylester styrene soil mortars made using Hanford soil. . . . . . . . 13

Figure 5 Polyester styrene soil mortars made using Hanford soil. . . . . . . . . . 14

Figure 6 Heated double action planetary mixer. $\ldots \ldots \ldots \ldots$

Figure 7 Modified sulfur cement soil mortars made using Hanford soil. . . . . . . 17

Figure 8 Methacrylate soil mortars made using Hanford soil. . . . . . . . . 18

Figure 9 Change in compressive strengths of Hanford soil mortars after 90 days water immersion. . . . . . . . . . . . . . . 20

Figure 10 Photograph modified sulfur cement Hanford soil mortars after 5 days immersion in water. .................. 21

Figure 11 Temperature history for one cycle of the thermal cycling test of Hanford soil mortars. . . . . . . . . . . . . . . . . 23

Figure 12 Change in compressive strengths of Hanford soil mortars after thermal cycling. ........................ 24

Figure 13 Change in compressive strengths of Hanford soil mortars after gamma irradiation to $10^{8}$ rad.

Figure 14 Weight history of vinylester styrene Hanford soil mortars subjected to wet-dry cycling.

Figure 15 Weight changes of vinylester styrene Hanford soil mortars subjected to wet-dry cycling. 


\section{LIST OF FIGURES (cont.)}

Page

Figure 16 Weight history of methacrylate Hanford soil mortars subjected to

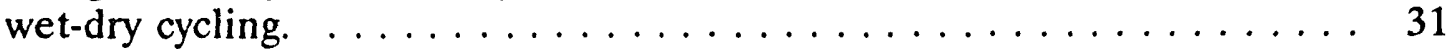

Figure 17 Weight changes of methacrylate Hanford soil mortars subjected to

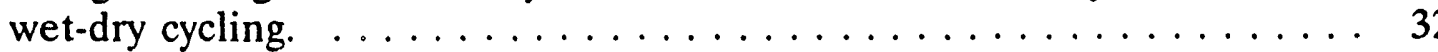

Figure 18 Weight history of polyester styrene Hanford soil mortars subjected to wet-dry cycling.

Figure 19 Weight changes of polyester styrene Hanford soil mortars subjected to wet-dry cycling.

Figure 20 Change in compressive strengths of Hanford soil mortars after

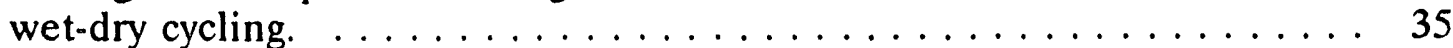

Figure 21 Photographs of Hanford soil mortars after 30 days exposure to $70^{\circ} \mathrm{C}$ nitrate brine.

Figure 22 Change in compressive strengths of Hanford scil mortars after 60 days exposure to $70^{\circ} \mathrm{C}$ nitrate brine. 


\section{LIST OF TABLES}

Page

Table 1 Potential Placement Technologies for Subterranean Containment Barriers ........................ 5

Table 2 Properties of candidate binder materials for subterranean barriers for USTs $\ldots \ldots \ldots \ldots \ldots \ldots \ldots \ldots$

Table 3 Soil Mortar Formulations $\ldots \ldots \ldots \ldots \ldots \ldots \ldots \ldots$

Table 4 Unconfined Compressive Strengths of Polymer-Soil Mortars . . . . . . . 12

Table 5 Compressive Strengths of Soil Mortars After 90 days Water Immersion . . 19

Table 6 Compressive Strengths of Soil Mortars After Thermal Cycling . . . . . . 22

Table 7 Compressive Strength of Irradiated Soil Mortar Composites . . . . . . 25

Table 8 Weight Changes of Samples Subjected to Wet-Dry Cycling . . . . . . 28

Table 9 Compressive Strengths of Soil Mortar Samples After Wet-Dry Cycling . . 28

Table 10 Estimated Chemical Composition of Supernatant for Single-Shell _ . . 36

Table 11 Compressive Strengths of Soil Mortars After Exposure to $70^{\circ} \mathrm{C}$ Nitrate Brine .......................... 39

Table 12 Hydraulic Conductivity of Hanford Soil Mortars . . . . . . . . . . . . . 40 


\section{INTRODUCTION}

The U.S. Department of Energy (DOE) set up the Underground Storage Tank Integrated Demonstration Program (USTID) to demonstrate technologies for the retrieval and treatment of tank waste, and closure of underground storage tanks (USTs). There are more than 250 underground storage tanks throughout the DOE complex. These tanks contain a wide variety of wastes including high level, low level, transuranic, mixed and hazardous wastes. Many of the tanks have performed beyond the designed lifetime resulting in leakage and contamination of the local geologic media and groundwater. To mitigate this problem it has been proposed that an interim subterranean containment barrier be placed around the tanks (Figure 1). This would minimize or prevent future contamination of soil and groundwater in the event that further tank leakages occur before or during remediation. Use of interim subterranean barriers can also provide sufficient time to evaluate and select appropriate remediation alternatives.

The DOE Hanford site was chosen as the demonstration site for containment barrier technologies. The demonstration site is located in a semi-arid region of southeastern Washington state. Annual precipitation is $15.9 \mathrm{~cm}\left(6.25^{\prime \prime}\right)$ with the largest percent falling during the cooler months from November to February. Evaporation exceeds precipitation by $5-9$ times with annual groundwater recharge rates of $0-10 \mathrm{~cm}\left(0-4^{\prime \prime}\right)$. The groundwater aquifer is $60-75 \mathrm{~m}(200-250 \mathrm{ft}$.) below surface. Typical soil moisture ranges from 1.5 to $3.5 \%($ surface $5-10 \mathrm{ft}=5-10 \%) \cdot\left[^{1}\right]$

The tank chosen for the subterranean containment barrier demonstration is Tank 106-C located in the 241-C Tank Farm Area. This tank comes under the control of the Hanford Federal Facility Agreement and Consent Order of 1989 which calls for interim stabilization by September 1996. Interim stabilization includes physical isolation of the tank. Tank 106-C is a single shell storage facility, $75 \mathrm{ft}$ in diameter, has a capacity of 533,000 gals., and first received waste in 1947 . The designed lifetime of the barrier is conservatively set at 25 years.

A panel of experts for the USTID was convened in February, 1992, to identify technologies for placement of subterranean barriers. The selection was based on the ability of candidate grouts to withstand high radiation doses, high temperatures and aggressive tank waste leachates. The group identified and ranked nine grouting technologies that have potential to place vertical barriers and five for horizontal barriers around the tank (Table 1). $\left[{ }^{2}\right]$ The panel also endorsed placement technologies that require minimal excavation of soil surrounding the tanks. The two placement methods given high ratings were jet grouting (Figure 2) and permeation grouting (Figure 3). 


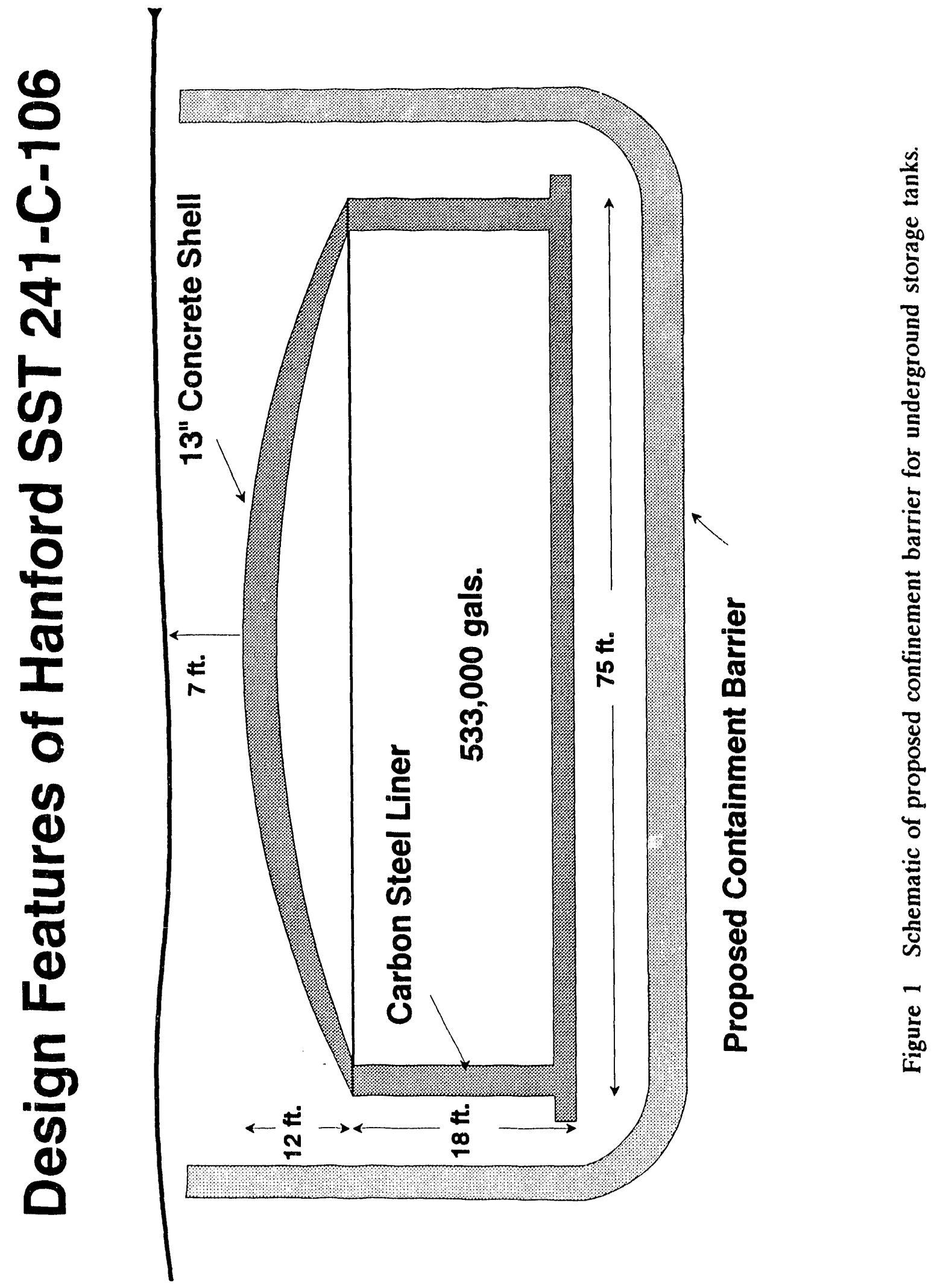




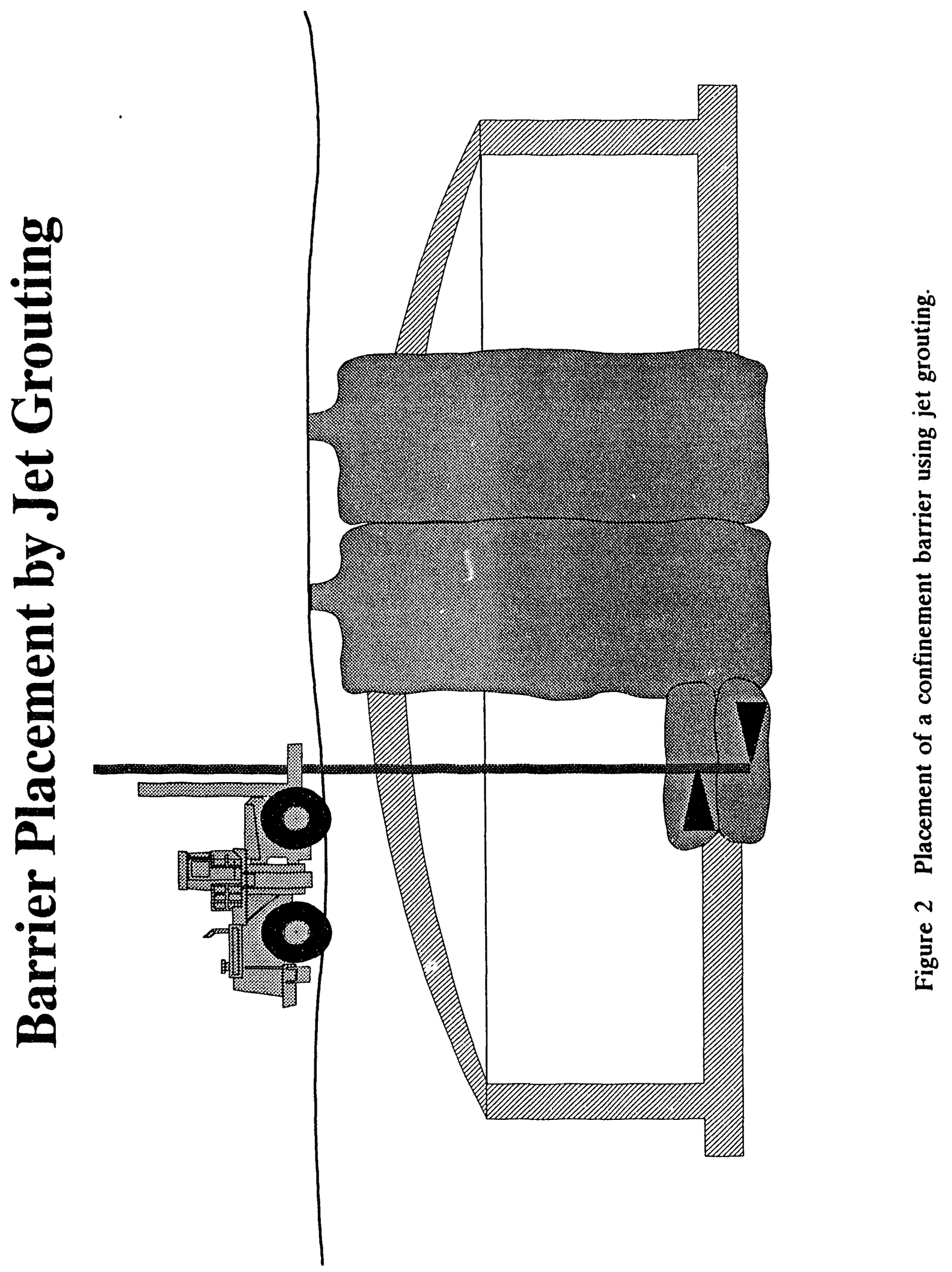




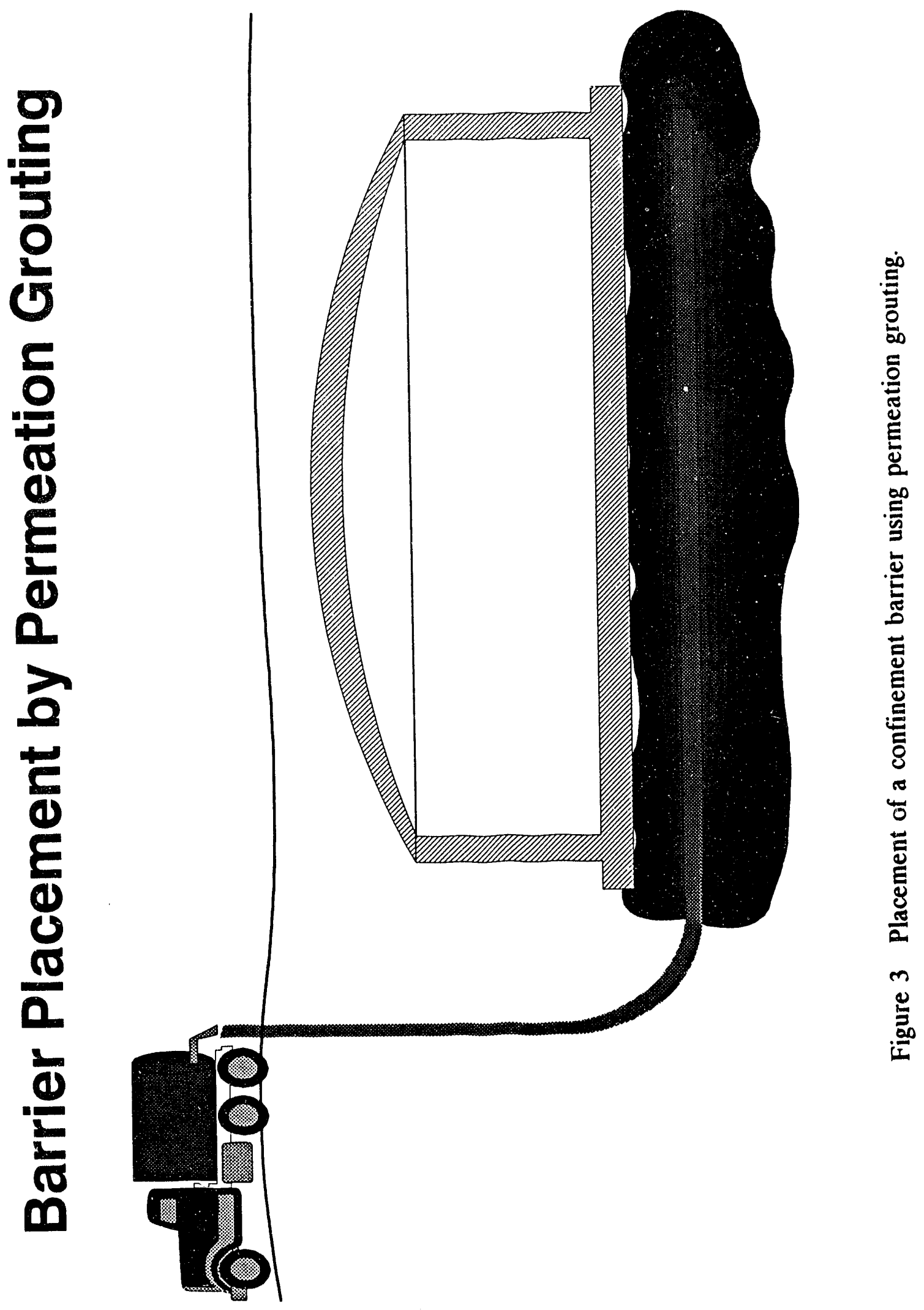


Table 1 Potential Placement Technologies for Subterranean Containment Barriers[2]

\begin{tabular}{|l|c|c|}
\hline Placement Technology & $\begin{array}{c}\text { Rating for Vertical Barrier } \\
\text { Placement }\end{array}$ & $\begin{array}{c}\text { Rating for Horizontal } \\
\text { Barrier Placement }\end{array}$ \\
\hline \hline Cement Slurry Wall & High & NA \\
\hline Deep Soil Mixing & Medium & NA \\
\hline In Situ Vitrification & Low & High \\
\hline Jet Grout Curtain & High & Medium \\
\hline Ground Freeze Barriers & Medium & Medium \\
\hline Modified Sulfur Cement & Medium & High \\
\hline Permeation Grouting & High & NA \\
\hline $\begin{array}{l}\text { Polymer Impregnated } \\
\text { Concrete }\end{array}$ & Low & NA \\
\hline Sheet Metal Pilings & High & \\
\hline
\end{tabular}

NA $=$ not applicable

Construction of a subterranean barrier by injection requires the grout material to completely penetrate the soil and remain in place until solidification is complete. The solidified monolith must then provide an impermeable and durable barrier. The ability of the grout to penetrate the soil is dependent on the liquid binder viscosity and the permeability of the soil. A coarse sandy soil can be injected with a higher viscosity binder at low to moderate pressures while a fine sand might require a near water viscosity resin applied at higher pressures. The viscosity of the injection grout and the "curing time" will also determine whether the binder remains in place or percolates away from the injection zone prior to hardening. A low viscosity material applied to a coarse sand may "run out" leaving a more permeable barrier after solidifying. The soil types involved in the USTID vary from clays (e.g., Savannah River) to coarse sands and gravel (e.g., Hanford). In general, it is desirable to develop several durable binders over a wide range of viscosities ( $\sim 1$ to $300 \mathrm{cps})$ to accommodate soil conditions at the various DOE sites. The most commonly used grout materials (i.e., suspension grouts) for cutoff curtains achieve permeabilities of $1 \times 10^{-9} \mathrm{M} / \mathrm{sec}$ under the best conditions. The goal for polymer-soil composite barriers is to achieve high durability barriers with permeabilities of $1 \times 10^{-11}$ $\mathrm{M} / \mathrm{sec}$ or less. 
In March, 1992, Brookhaven National Laboratory began a program to define, develop, and characterize advanced polymer systems for in situ applications at the Hanford UST site.

The scope of this program is to investigate polymer materials that can be used with the high rated placement technologies. It is recognized that some modifications to the placement technologies may be required to meei the characteristics of individual polymer systems. However, this is not within the scope of this program and will be considered as the technology progresses. This report describes the initial work performed on several polymer-soil composites. 


\section{MATERIALS}

Based upon site geochemical and geophysical characteristics, and UST performance requirements, BNL's two candidate polymer grout systems were selected for development and characterization as barrier materials. The two grouts are polymer concrete and sulfur concrete. Both polymer concrete and sulfur concrete are innovative materials with desirable properties in both their fluid and solid states which make them suitable for applications where impermeability, high strengths, and long-term durability are required. These materials have been extensively used in many commercial applications such as in sewage and brine handling systems, and electrolytic baths. They have also been used by the Corps of Engineers to repair dams and canal locks, and by the Federal Highway Administration for bridge deck and highway repairs. Theis impermeability to gases and liquids, combined with resistance to radiation, acidic and alkaline environments, make polymer grouts candidates for high quality barrier materials.

Polymer concrete is defined as an aggregate mixed with a liquid monomer or resin (binder) which is converted in place, to form a hard polymer monolith. This material can be mixed and cast in the field. Candidate binders were selected based on durability of the polymer and chemical and physical characteristics of the resin (i.e., viscosity). These included methacrylates, vinyl-ester styrene, polyester styrene, furfuryl alcohol, and polyacrylic acids. Some properties of the candidate binders are given in Table 2 . These binders are classified as thermosets. Thermosetting polymers require a chemical reaction to convert monomer to polymer. Once formed they cannot be reformed or remelted.

The polymerization of unsaturated monomers such as methacrylates and polyesterstyrene is typically a chain reaction. Polymerization can be initiated by the action of a free radical on a monomer molecule, which leads to polymer chains consisting of thousands of monomer molecules. Free radicals can be formed by the decomposition of a relatively unstable material called an initiator or a catalyst. Benzoyl peroxide is a commonly used initiator. When subjected to heat or in the presence of a promoter, the peroxide molecule splits at the $0-0$ bond to form two free radicals that have unpaired electrons and are thus very reactive.

Promoters can be used instead of temperature for ambient temperature curing of catalyzed monomer systems. Promoters (also called accelerators) are chemical compounds that induce the decompusition of a peroxide catalyst by breaking the $0-0$ bond. This reaction can take place over a wide temperature range, depending on the promoter-catalyst system used. This is the preferred method for in-situ applications.

Cure time is dependent upon temperature, promoter-catalyst combination and concentration, and admixtures that may retard or enhance the set. The reaction is exothermic and results in an autoaccelerating reaction that must be properly controlled. Thermosetting polymers have been developed to solidify radioactive, mixed, and hazardous waste. $[3,4,5,6]$ 
Table 2 Properties of candidate binder materials for subterranean barriers for USTs ${ }^{a}$

\begin{tabular}{|c|c|c|c|c|c|c|}
\hline Property & $\begin{array}{l}\text { Modified } \\
\text { Sulfur } \\
\text { Cement } \\
\text { (MSC) } \\
\text { Chement } \\
2000\end{array}$ & $\begin{array}{l}\text { Polyester- } \\
\text { Styrene } \\
\text { (PES) } \\
\text { Atlac }\end{array}$ & $\begin{array}{l}\text { Vinyl } \\
\text { Ester } \\
\text { Styrene } \\
\text { (VES) } \\
\text { Derakane } \\
470-45\end{array}$ & $\begin{array}{l}\text { Methacrylate } \\
3 \mathrm{M} \mathrm{4R}\end{array}$ & $\begin{array}{l}\text { Acrylate } \\
\text { AC- } 400\end{array}$ & $\begin{array}{l}\text { Furfuryl } \\
\text { Alcohol }\end{array}$ \\
\hline $\begin{array}{l}\text { Viscosity, } \\
\text { cps }\end{array}$ & $\begin{array}{c}28 @ \\
135^{\circ} \mathrm{C}\end{array}$ & $300 @ 25^{\circ} \mathrm{C}$ & $\begin{array}{c}100 @ \\
25^{\circ} \mathrm{C}\end{array}$ & $\begin{array}{l}5 @ \\
25^{\circ} \mathrm{C}\end{array}$ & $\begin{array}{l}3 @ \\
2^{n \circ} \mathrm{C}\end{array}$ & $\begin{array}{l}3 @ \\
20^{\circ} \mathrm{C}\end{array}$ \\
\hline $\begin{array}{l}\text { Specific } \\
\text { gravity }\end{array}$ & 2.07 & 1.03 & 1.048 & 1.025 & 1.18 & 1.14 \\
\hline $\begin{array}{l}\text { Flashpoint } \\
\left({ }^{\circ} \mathrm{C}\right)\end{array}$ & 191 & 32 & $21-32$ & 105 & NF & 77 \\
\hline
\end{tabular}

anformation taken from manufacturers Material Safety Data Sheets.

$\mathrm{NF}=$ non flammable

Sulfur concrete consists of an aggregate bound with modified sulfur cement (MSC). MSC is a thermoplastic polymer. Thermoplastic materials when heated above their melting points become liquid and can be mixed with an aggregate filler such as sand or soil. Upon cooling the mix re-solidifies to form a solid monolith. No chemical reaction is required for setting (as in hydraulic cements), thus minimizing incompatibilities between binder and aggregate. Thermoplastics such as polyethylene and MSC have been used for chemically resistant flooring and reactor vats[7] and have been developed for solidification of various wastes. $[8,9,10]$

For the Hanford demonstration it is desirable to have a placement technology that does not require excavation of potentially contaminated soils. The aggregate is the natural soil as it exists around the tanks. For this report, the grouting materials are defined as "mortars" or "soil mortars" and consist of the polymer binders mixed with Hanford soil. A description of the binder materials follows.

\subsection{Methacrylates}

Methacrylate monomers are a low viscosity, inexpensive, and commonly used family of polymers. The methacrylate chosen is manufactured by the $3 \mathrm{M}$ company under the 
tradename $3 \mathrm{M} 4 \mathrm{R}$ Concrete Restorer and is a modified high molecular weight methacrylate. The system consists of dicyclopentadienyl methacrylate and isooctyl acrylate and is polymerized using a cobalt octoate promoter (reducing agent) and cumene hydroperoxide initiator (oxidative catalyst).

\subsection{Polyester Styrene}

Polyester styrenes (PES) are among the most widely usec thermosetting resins. The basic components of a PES polymer consist of a mixture of a linear polyester resin and styrene monomer. Chemical and physical characteristics of the final polymer are dependent on the choice of polyester resin and styrene content. For the Hanford UST containment barrier, resistance to the strong alkali supernatants in the tanks is probably the most critical factor in choosing a PES system. For this reason BNL selected a modified bisphenol fumarate resin distributed by Reichhold Chemicals, under the tradename Atlac 4010A. This resin is especially formulated for alkali resistance. The Atlac PES requires a $6 \%$ cobalt naphthenate (CoN6) solution as the promoter and methlyethyl ketone peroxide (MEKP) as the initiator. The viscosity of the polyester-styrene solution is approximately 300 cps.

\subsection{Vinylester Styrene}

Vinylester styrene (VES) polymers are extremely durable both chemically and physically. These polymers have been used to encapsulate radioactive waste and in a wide variety of applications calling for resistance to harsh chemicals. $[4,11,12]$ The VES system used in this study is manufactured by DOW Chemicals under the tradename Derakane $470-45$ and is an epoxy novolac- based vinyl ester resin dissolved in styrene. This particular Derakane was formulated for good chemical resistance (including solvents), retention of properties at high temperatures and has a low viscosity. The polymerization occurs using an oxidation-reduction reaction. Dimethylaniline (DMA) promoter was used in conjunction with a $40 \%$ benzoyl peroxide (BPO) catalyst solution.

\subsection{Furfuryl Alcohol}

A commercial grade furfuryl alcohol (FA) was used for this study. FA has a low viscosity, low vapor pressure, low flammability, and is soluble in water. This material produces a very resistant polymer using cheap and environmentally innocuous components. FA has been used in the fabrication of polymer concrete pipes, as an organic cementing and sand consolidating material in oil wells, floor coatings, and chemically resistant containers. Polymerization of furfuryl alcohol occurs through a condensation reaction using a strong acid catalyst. Basic reagents tend to inhibit the polymerization.[13] Set times and exotherms cannot be as tightly controlled as in the other polymer systems. For this study the catalyst used was p-toluene sulfonic acid. 


\subsection{Polyacrylic Acid}

Polyacrylic acid, under the tradename AC-400 (Geochemical Corporation) is among the most widely used hydraulic barrier materials for construction applications in the United States. This material, a magnesium acrylate, produces a soft gel rather than a hard solid with typical compressive strengths of 50 psi. AC-400 is commonly used to seal sewer pipe leaks and to stop water infiltration at construction sites. Acrylate grouts have been shown to have low water permeabilities and to be resistant to a large number of chemicals.[14] Acrylate grout gels typically contain $80-90 \%$ water and are extremely sensitive to wet-dry and freeze-thaw cycling. Such high water content gels wc rk best in $100 \%$ humidity or water submerged conditions. The soft gels are also prone to creep fatigue failures and can fail with loadings as low as $20 \%$ of the unconfined compressive strength (UCS).[15] Acrylate grouts behave similarly to the acrylamide grouts and have quickly replaced the latter due to lower toxicities (1/100th of acrylamide grouts). Polymerization occurs using triethanolamine (TEA) catalyst and ammonium persulfate (AP) initiator. Gel time is variable from 5 seconds to 1 hour and can be adjusted by adding potassium ferricyanide $\left(\mathrm{KFe}[\mathrm{CN}]_{6}\right)$, an inhibiting agent. $\mathrm{AC}-400$ was investigated due to the high use in construction, existing placement technologies, and interest from several outside parties.

\subsection{Modified Sulfur Cement}

Modified sulfur cement is a sulfur polymer developed by the U.S. Bureau of Mines to utilize surplus sulfur.[16] Sulfur concretes offer excellent chemical resistance to strong acids and salts and are relatively inexpensive. MSC is used for construction of chemical vats, road repairs, and is a candidate for encapsulating radioactive, hazardous, and mixed wastes.[7,17] MSC is formed by reacting elemental sulfur with dicyclopentadiene and oglimers of cyclopentadiene. This modification to elemental sulfur suppresses a crystalline phase change that occurs as sulfur cools below $95.6^{\circ} \mathrm{C}$. In unmodified sulfur, the monoclinic form of sulfur changes to the orthorhombic form with a resultant density increase and an introduction of stresses. Such residual stresses make sulfur susceptible to shock damage by impact or thermal changes. The sulfur cement used in this study was manufactured by Martin Chemicals under the trade name Chement 2000. MSC is a thermoplastic material that melts at $119^{\circ} \mathrm{C}$. When heated above its melting point MSC can be mixed with aggregate, soil, waste, etc., and upon cooling forms a hard monolithic solid. Full strength is achieved in hours rather than weeks as compared to hydraulic cements. 


\section{FORMULATIONS}

The polymer systems chosen had to be optimized to the chemical and physical properties of the Hanford soil. A sample of soil was obtained from a clean area of the Hanford 200 series tank farm. The soil is a coarse brown sand with a measured soil pH of 9.0 (ASTM D-4972).[18] Moisture content is reported to be 1-3\% in the areas around the demonstration tank, although the soil sample received from PNL contained 5.8\% moisture. The first set of experiments were designed to determine the effect of soil aggregate on the resin gel times. Because of the alkali nature of the soil it was postulated that problems would occur using furfuryl alcohol due to the acidic characteristics of the catalyst. This is the only system where difficulties in solidifying the soils were predicted. Choosing 1-2 hours as a reasonable working time prior to polymer gelling, samples of monomer were allowed to cure with and without soil aggregate. The furfuryl alcohol failed to gel with added Hanford soil because of the neutralizing effect of the high $\mathrm{pH}$ soil on the acid catalyst. All other systems followed expected gel times, with and without Hanford soil. This initial trial eliminated furfuryl alcohol as a candidate material for Hanford soil grout barrier technologies. However, placement technologies that rely on displacement/replacement methods where the subterranean soils are "pushed away" (displaced) by the barrier material or removed and replaced by the barrier material might still use furfuryl alcohol with a neutral silica aggregate.

After confirmation of catalyst-promoter quantities to achieve reasonable gel times sample fabrication techniques were refined. Porosity of the soil surrounding the tanks was estimated to be $35-45 \%$ based on the coarseness of the soil sample received from Hanford. This would correspond to approximately $20-25 \%$ by weight monomer required to fill the void volume of the soil. The soil samples received were unconfined and attempts to replicate the density of the confined soils would be difficult and unnecessary at this time, since an exact placement technology has not yet been chosen. Of primary importance is the interaction of the monomer/soil composite and its durability properties. BNL attempted to balance the requirement of staying near 20-25 wt\% monomer and produced laboratory samples that were reproducible and homogeneous.

VES and PES soil mortar samples were fabricated by mixing together the as received soil with resin, promoters and catalysts in a Hobart mixer. The mixture was poured into 3.5 foot long $x 1.5$ inch diameter PVC pipe. After polymerization was completed, the pipe was cut into 3 inch lengths, the samples were removed from the mold and the samples were measured and weighed to check for homogeneity within each lot. Multiple lots of each binder-combination were fabricated, cut to length and allowed to set in this manner. Three samples (top, middle, and bottom) from each lot were tested for unconfined compressive strength (ASTM D-695)[19] to determine baseline strength and for homogeneity within each lot and between lots. Resultant values showed low scatter and no lot to lot variation which is evidence of good homogeneity. Formulations and baseline strengths are given in Tables 3 and 4. Photographs of VES and PES soil mortars are shown in Figures 4 and 5 , respectively. 
Table 3 Soil Mortar Formulations

\begin{tabular}{||l|c|c|c|c||}
\hline \multicolumn{1}{|c|}{ Polymer } & $\begin{array}{l}\text { Soil } \\
\text { (by wt.) }\end{array}$ & $\begin{array}{c}\text { Binder } \\
\text { (by wt.) }\end{array}$ & $\begin{array}{c}\text { Catalyst } \\
\text { phr (\%) }\end{array}$ & $\begin{array}{c}\text { Promoter } \\
\text { phr (\%) }\end{array}$ \\
\hline \hline Methacrylate & 76 & 23 & 3 & 1 \\
\hline Polyester-Styrene & 72 & 27 & 2.4 & 1 \\
\hline $\begin{array}{l}\text { Vinylester- } \\
\text { Styrene }\end{array}$ & 75 & 25 & 2.5 & 0.1 \\
\hline Sulfur Cement & 70 & 30 & N.A. & N.A. \\
\hline Acrylate & 82 & 18 & 1 & 1 \\
\hline Furfuryl Alcohol & N.A. & N.A. & $0.5-2.0$ & - \\
\hline
\end{tabular}

N.A. $=$ not applicable

phr $(\%)=$ per hundred parts of resin by weight

$\mathrm{a}=12 \%$ solids

Table 4 Unconfined Compressive Strengths of Polymer-Soil Mortars

\begin{tabular}{||c|c|c||}
\hline Material & Strength, psi [MPa] & $\begin{array}{l}\text { Standard } \\
\text { deviation }\end{array}$ \\
\hline \hline VES & $6910[47.6]$ & $385[2.65]$ \\
\hline PES & $7120[49.1]$ & $522[3.60]$ \\
\hline Methacrylate & $3730[25.7]$ & $383[2.64]$ \\
\hline Sulfur Cement & $4440[30.6]$ & $838[5.78]$ \\
\hline MSC lot \#1 & $5760[39.7]$ & $136[0.94]$ \\
\hline MSC lot \#2 & $5180[35.7]$ & $309[2.13]$ \\
\hline MSC lot \#3 & $4500[31.0]$ & $364[2.51]$ \\
\hline MSC lot \#4 & $3560[24.5]$ & $226[1.56]$ \\
\hline MSC lot \#5 & $3470[23.9]$ & $157[1.08]$ \\
\hline MSC lot \#6 & $4240[29.2]$ & $37[0.26]$ \\
\hline
\end{tabular}



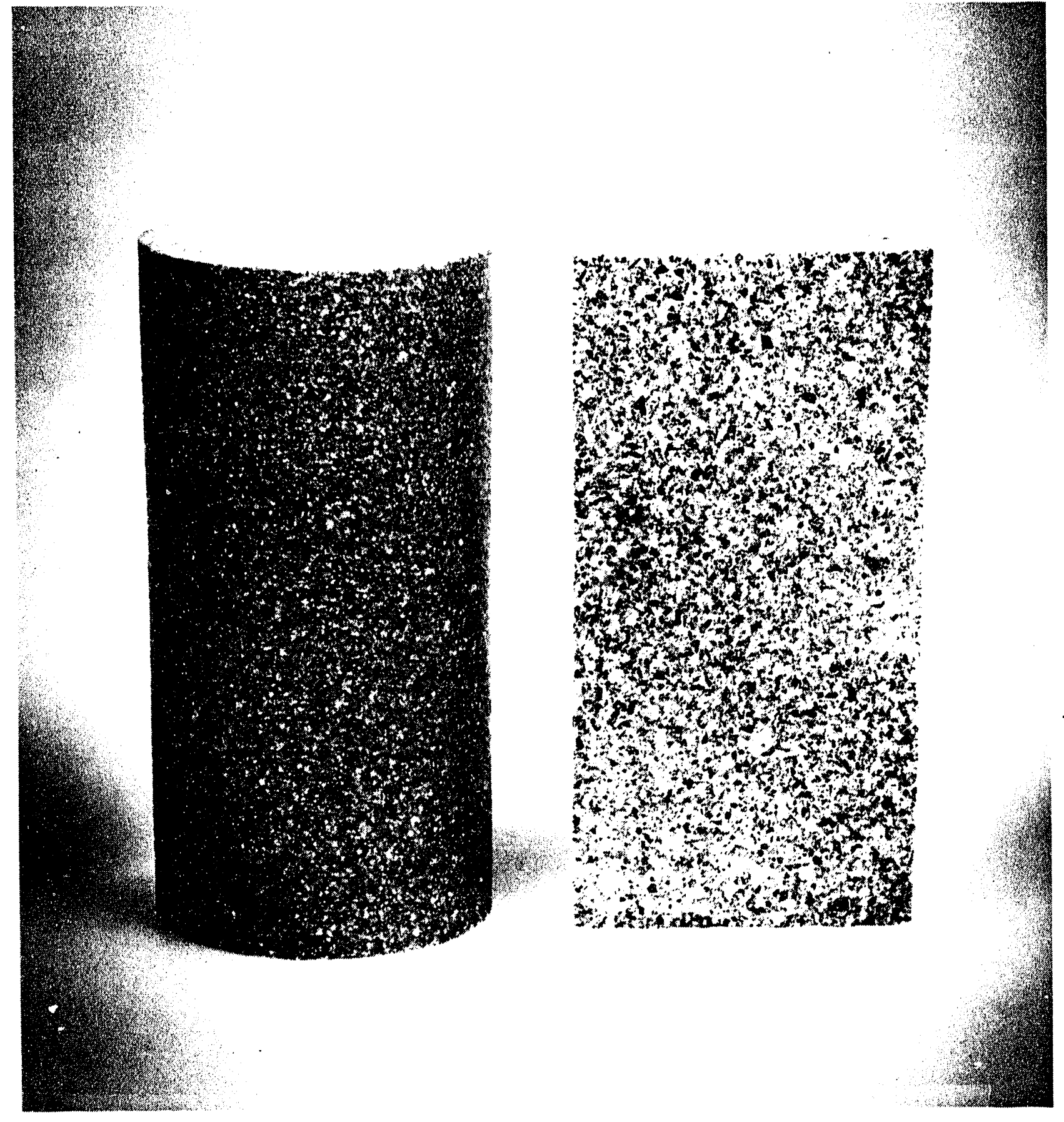

Figure 4 Vinylester styrene soil mortars made using Hanford soil. 

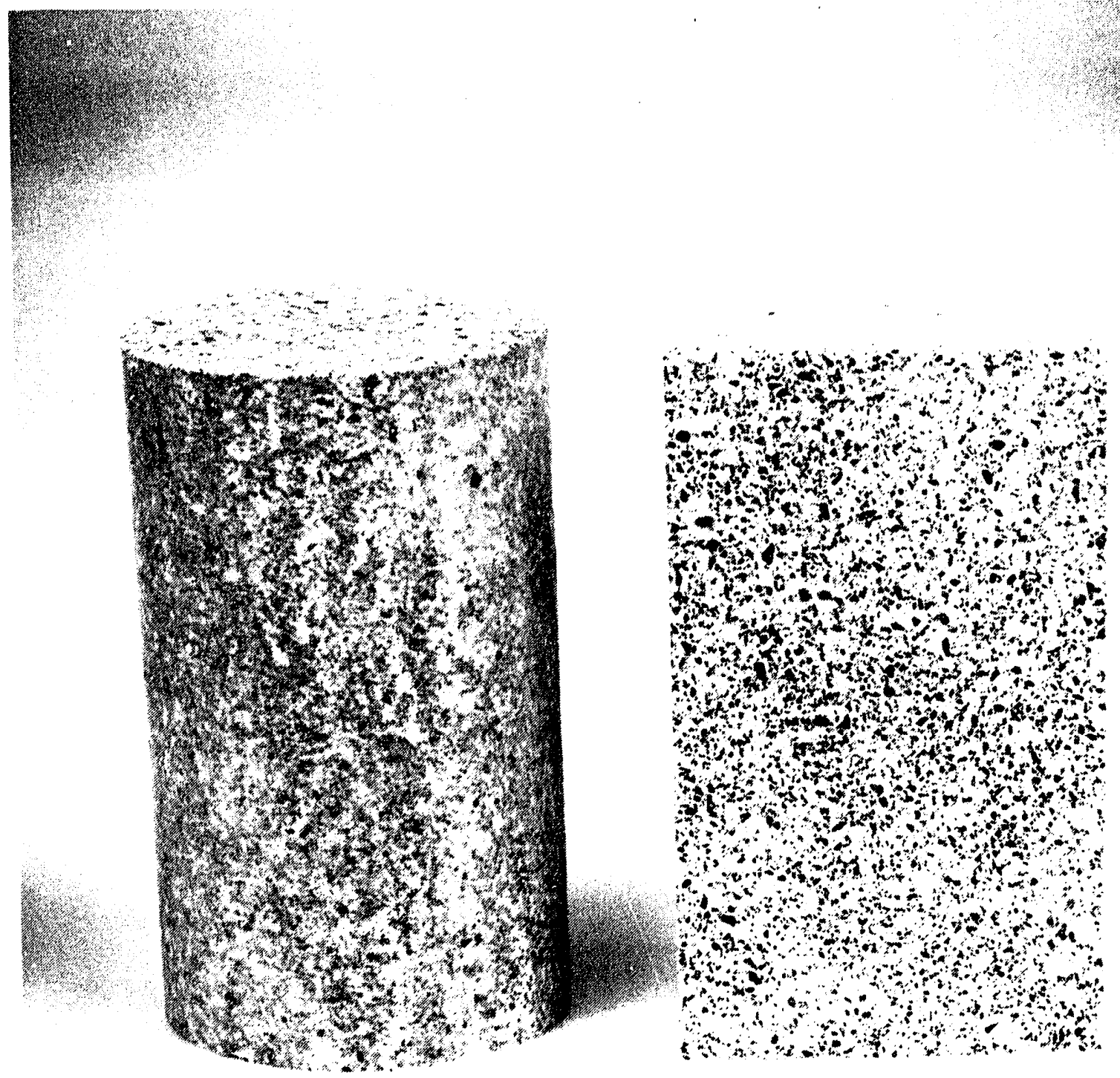

Figure 5 Polyester styrene soil mortars made using Hanford soil. 
The MSC samples were made by mixing MSC and soil in a heated double action planetary mixer (Figure 6). The lot was mixed until the temperature reached $124^{\circ} \mathrm{C}$ at which time the mixture was poured into two inch diameter PVC pipe, which was used as a casting mold. The lot was allowed to cool for several hours. After solidification of the mix, the pipe was cut into 4" lengths and the samples were removed from the PVC casing, measured, and weighed. The unconfined compressive strengths were measured (ASTM D695) for three samples from each lot. The samples showed very low scatter (UCS $=4440$ psi, avg. std. dev. $=206$ ) within each lot but much larger variation (std. dev. $=838$ ) between lots. Examination of the fractured samples indicated the presence of entrained air within the samples, possibly due to the high viscosity of the melt. It is postulated that the amount and size of these air bubbles is dependent upon mix viscosity, soil loading, mix speed and mix time. The effect of these variables may explain the lot to lot variability. For durability testing each sample of MSC was compared to the lot it came from. Formulation and baseline compressive strengths for total samples and individual lots are given in Tables 3 and 4. Figure 7 shows a photograph of a MSC soil mortar sample.

Soil mortar samples made with $3 \mathrm{M} 4 \mathrm{R}$ methacrylate were fabricated by mixing the resin and catalyst together, followed by the addition of the promoter. The prepared binder was then poured into a PVC mold followed by slowly adding a preweighed lot of soil. After solidification, the lot was cut into 3 inch lengths, the samples were removed from the mold and they were measured and weighed. Three samples were tested for unconfined compressive strength (ASTM D-695) and checked for homogeneity. No variations either within a lot or between lots resulted. Sample weights in any given lot typically ranged from 186 to $205 \mathrm{~g}$. There was a slight vertical weight variation within a given lot, amounting to 3-5\% of the average. These differences, however, did not manifest as differences in UCS. The formulations and UCS are given in Tables 3 and 4. A photograph is shown in Figure 8.

Initial samples made with AC-400 immediately showed problems. Samples were prepared utilizing a manufacturers recommended formulation. The binder was made up in two parts; solution one was 49 parts water and 1 part AP, solution two was 30 parts AC400 resin (40\% solids), 19 parts water (containing $.02 \%, \mathrm{KFe}[\mathrm{CN}]_{6}$ ), and 1 part TEA. The two solutions were then mixed, as needed, to form the final binder and induce polymerization. Samples were fabricated by filling a container with soil and subsequently flooding the soil, from the bottom, with the AC-400 binder. The gel formed was soft and produced a final composite with a compressive strength estimated to be less than 100 psi. The samples showed measurable dimensional changes after sitting for one hour at room temperature at $40 \%$ relative humidity. The observed behavior of AC-400 gels is as expected for extremely high water content gels and has been reported in the literature. However, the Hanford site is arid and as such, dry conditions will prevail. A barrier made using AC-400 would in time be prone to shrinkage and cracking. This conclusion is enforced by Karol ${ }^{17}$ who writes that "Long term tests ...indicate that grouts gain their full strengths immediately upon gelation and retain that strength (as long as freeze-thaw and wet-dry conditions do not exist)." The Manufacturer states "Under conditions that allow water to evaporate, AC-400 chemical grout will gradually dehydrate."[20] Based upon observations and literature reports, $\mathrm{AC}-400$ was eliminated as a candidate binder for PNL site specific polymer-soil mortar. 


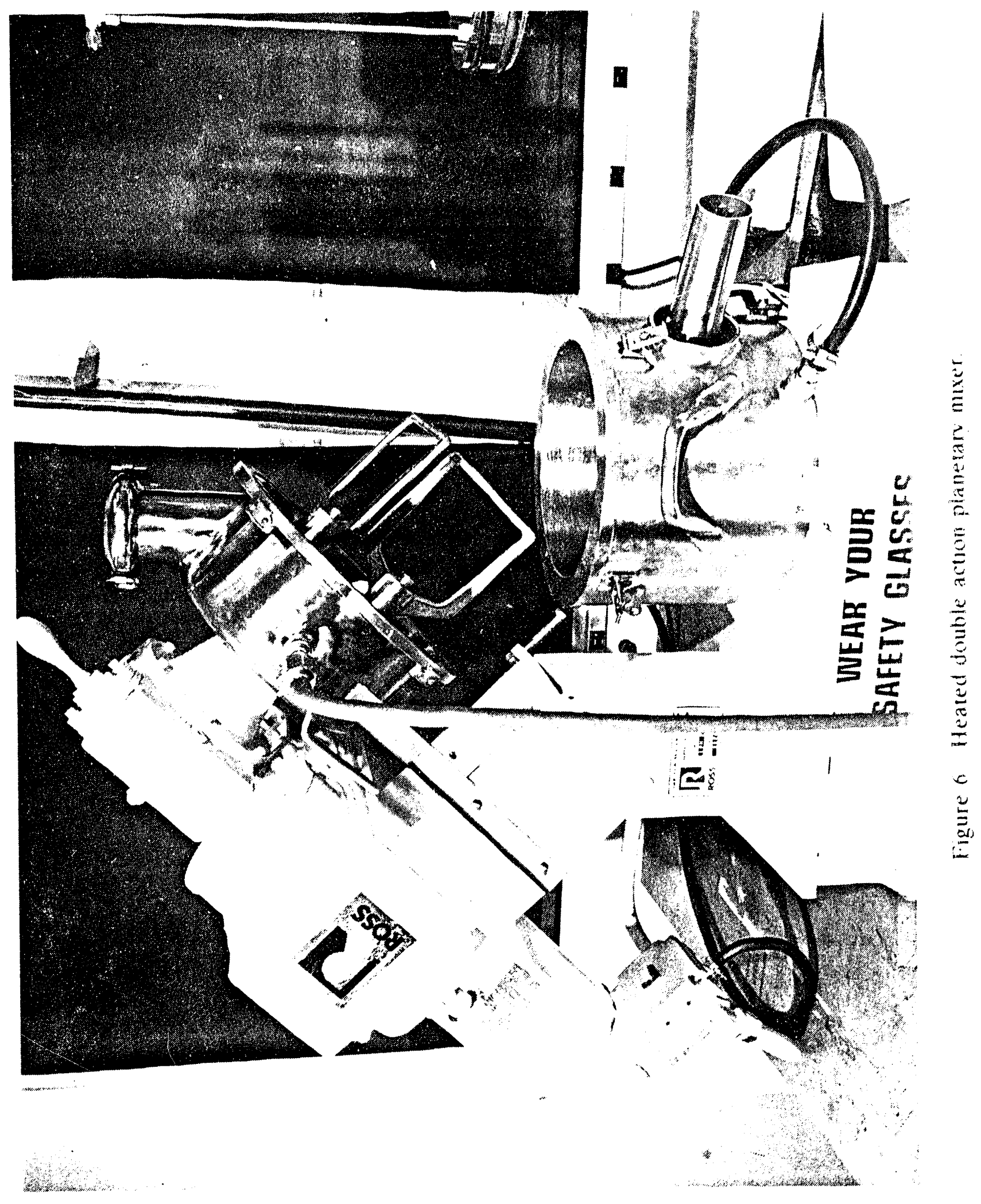




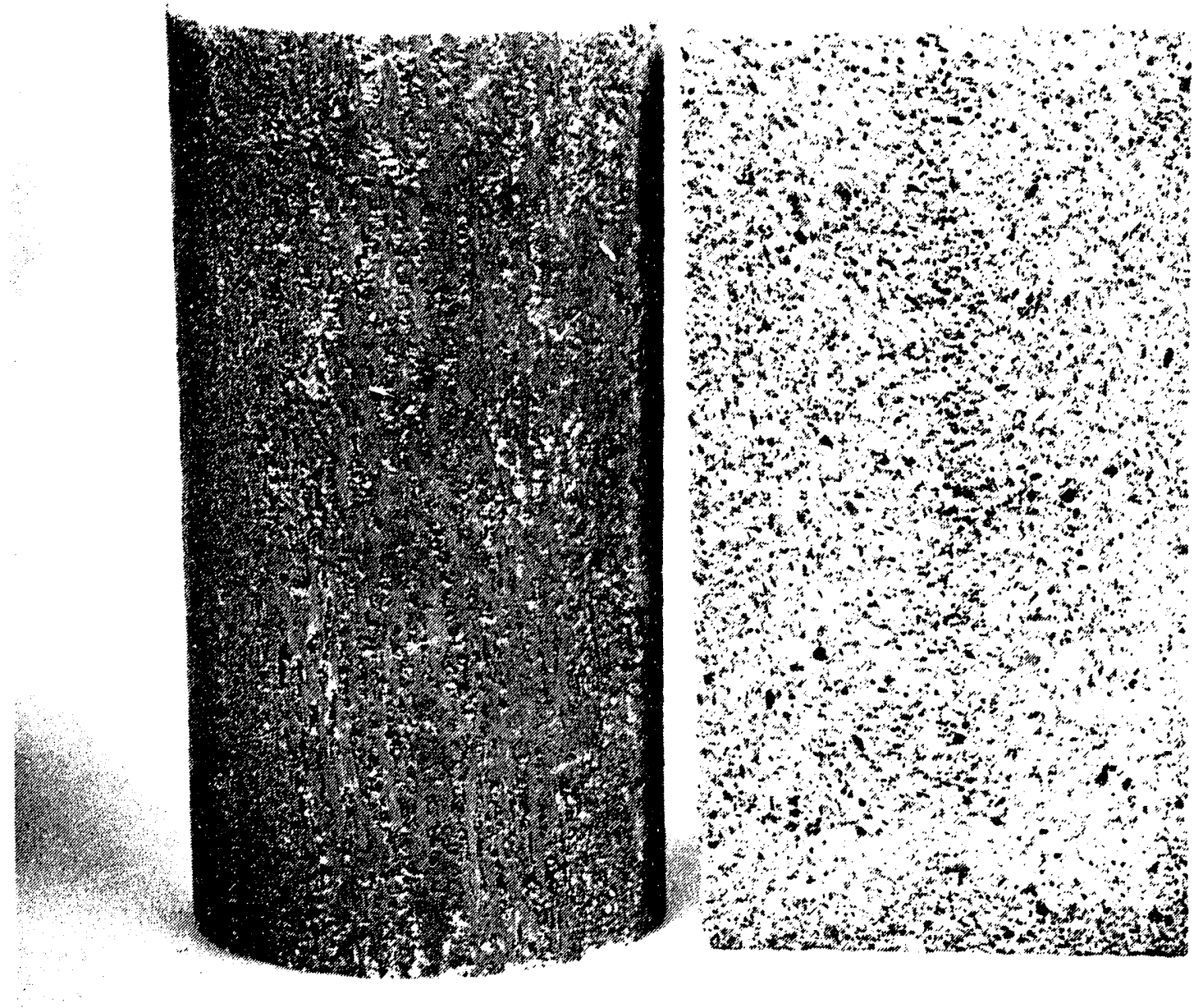

Figure 7 Modified sulfur cement soil mortars made using Hanford soil. 


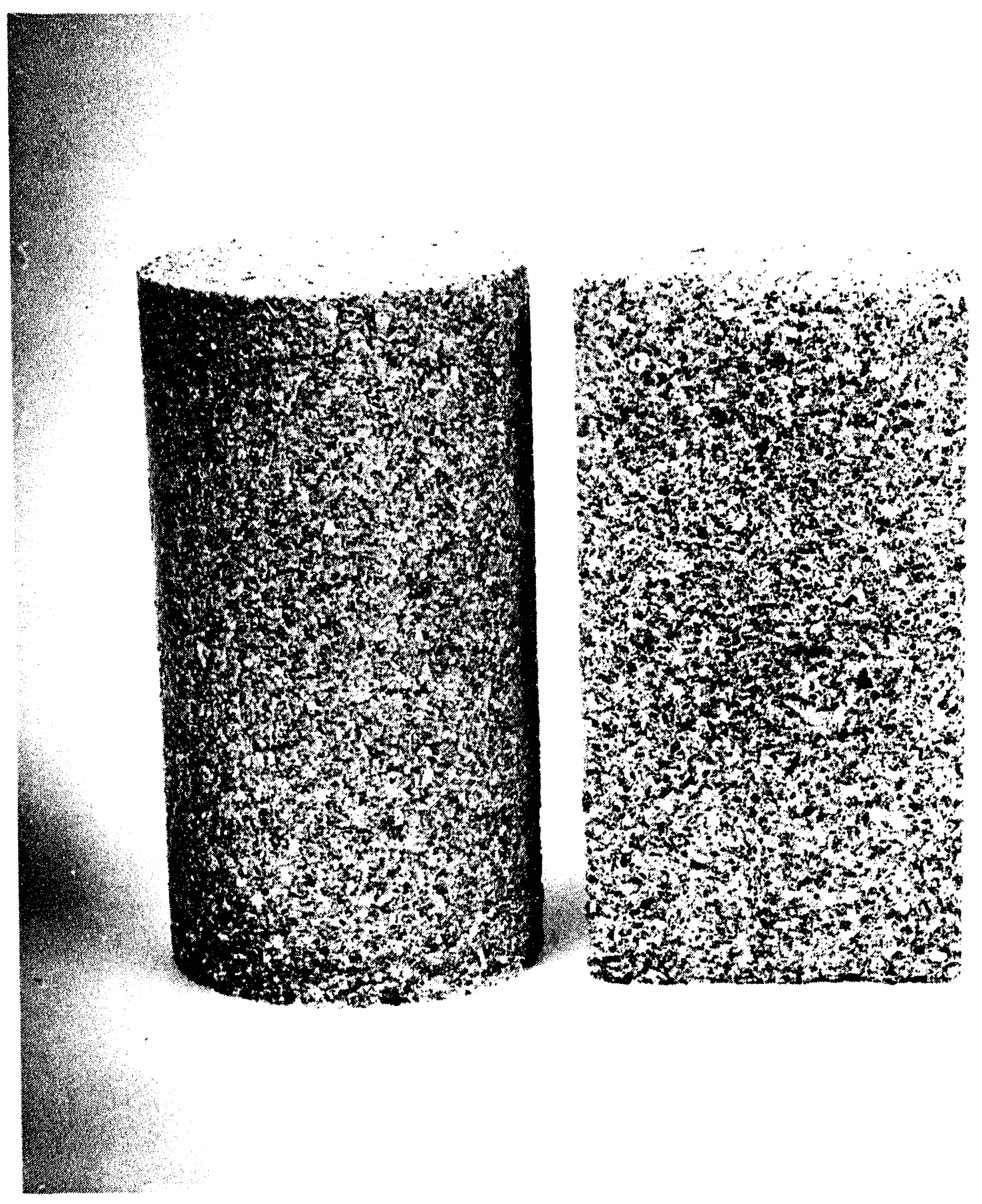

Figure 8 Methacrylate soil mortars made using Hanford soil. 


\section{TESTING}

The soil mortar samples for VES, PES, MSC, and methacrylate binders were subjected to a series of performance tests to determine if the materials were capable of meeting the requirements of a subterranean barrier for USTs, as follows:

\subsection{0-Day Water Immersion Test}

A subterranean containment barrier is expected to be exposed to aqueous environments either from leakage of the supernatant contained in the UST or percolate water. Exposure of barrier materials to aqueous solutions can result in swelling, cracking, dissolution, etc. The soils used as aggregate may also interact with the water through swelling (i.e., expansive clays) and dissolution of mineral components. Aggregate interactions can cause internal stresses with resultant cracking and strength losses in the barrier. Six replicate samples of each soil mortar combination were immersed in deionized water for a period of 90 days. Periodically, during the course of the test, the samples were visually inspected for cracking and swelling. At the end of the test period the samples were weighed, measured and destructively tested for compressive strength (ASTM D-695). With the exception of MSC no visual, dimensional, or significant strength changes were observed. Compressive strength data for VES, PES, and $3 \mathrm{M} 4 \mathrm{R}$ are given in Table 5 and Figure 9.

MSC samples cracked after three to five days exposure to ionized water. Figure 10 shows the MSC soil mortar samples before and after immersion. This effect is probably due to a small expansive clay portion in the Hanford soils which would induce tensile stresses in the sample when exposed to water. The effect of such expansive clays is most pronounced with MSC because of its low tensile strength. During the fabrication of MSC samples, temperatures in excess of $120^{\circ} \mathrm{C}$ are required to melt the binder. At these temperatures the residual soil moisture is driven off and the clays shrink to their minimum volume. When the clays are re-wetted they expand with resultant internal stresses. For all the other binders the soil was used as received, with approximately $5.6 \%$ moisture content, without showing detrimental effects. Perhaps the important factor assisting the other binders is their higher tensile strengths.

Table 5 Compressive Strengths of Soil Mortars After 90 days Water Immersion

\begin{tabular}{|l|c|c|c|}
\hline Material & $\begin{array}{c}\text { Post } \\
\text { Immersion psi } \\
{[\mathrm{MPa}]}\end{array}$ & std. dev. & \% change \\
\hline \hline VES & $7410[51.1]$ & $167[1.15]$ & +7 \\
\hline PES & $6880[47.4]$ & $186[1.28]$ & -3 \\
\hline 3 M 4R & $3340[23.1]$ & $554[3.83]$ & -11 \\
\hline
\end{tabular}




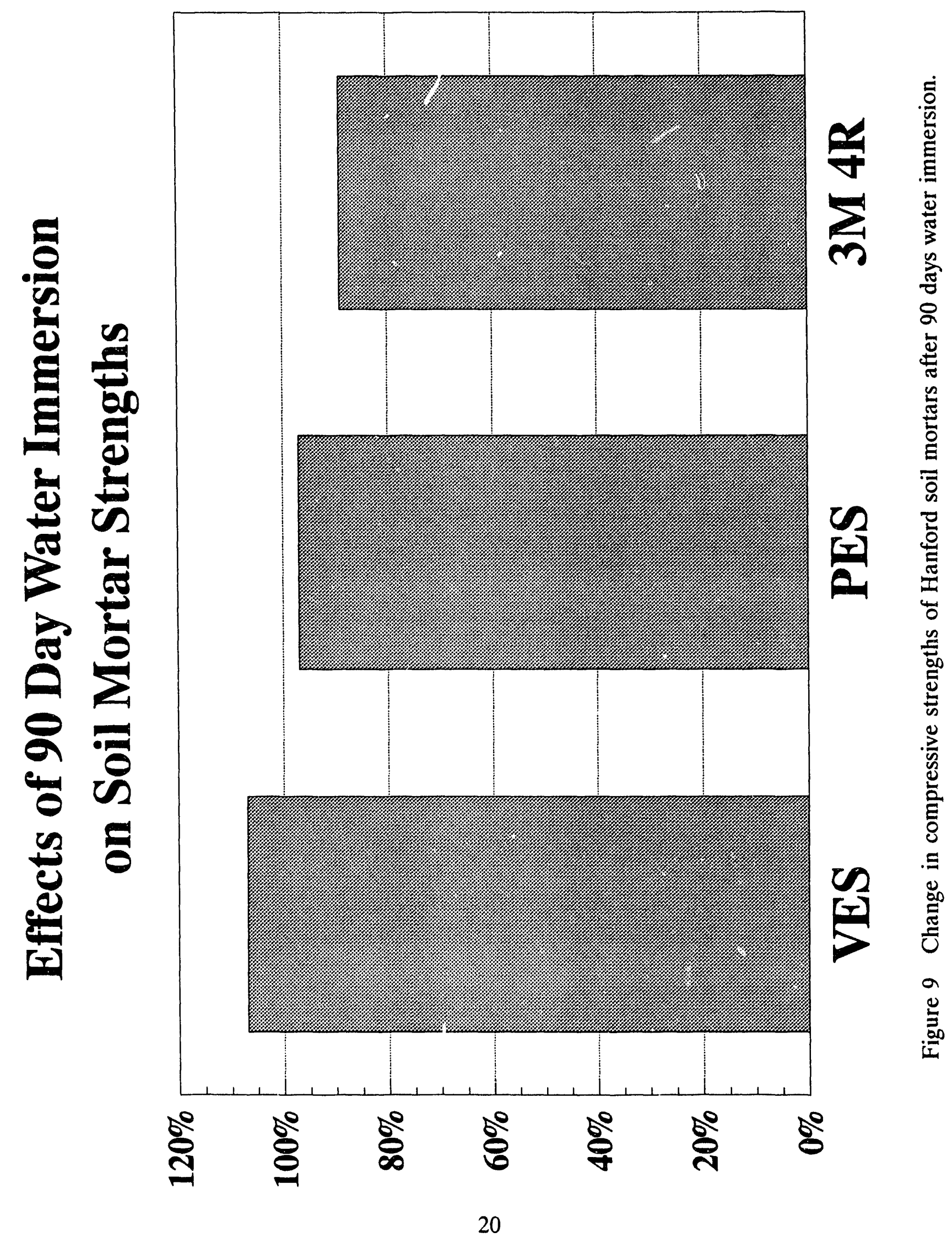



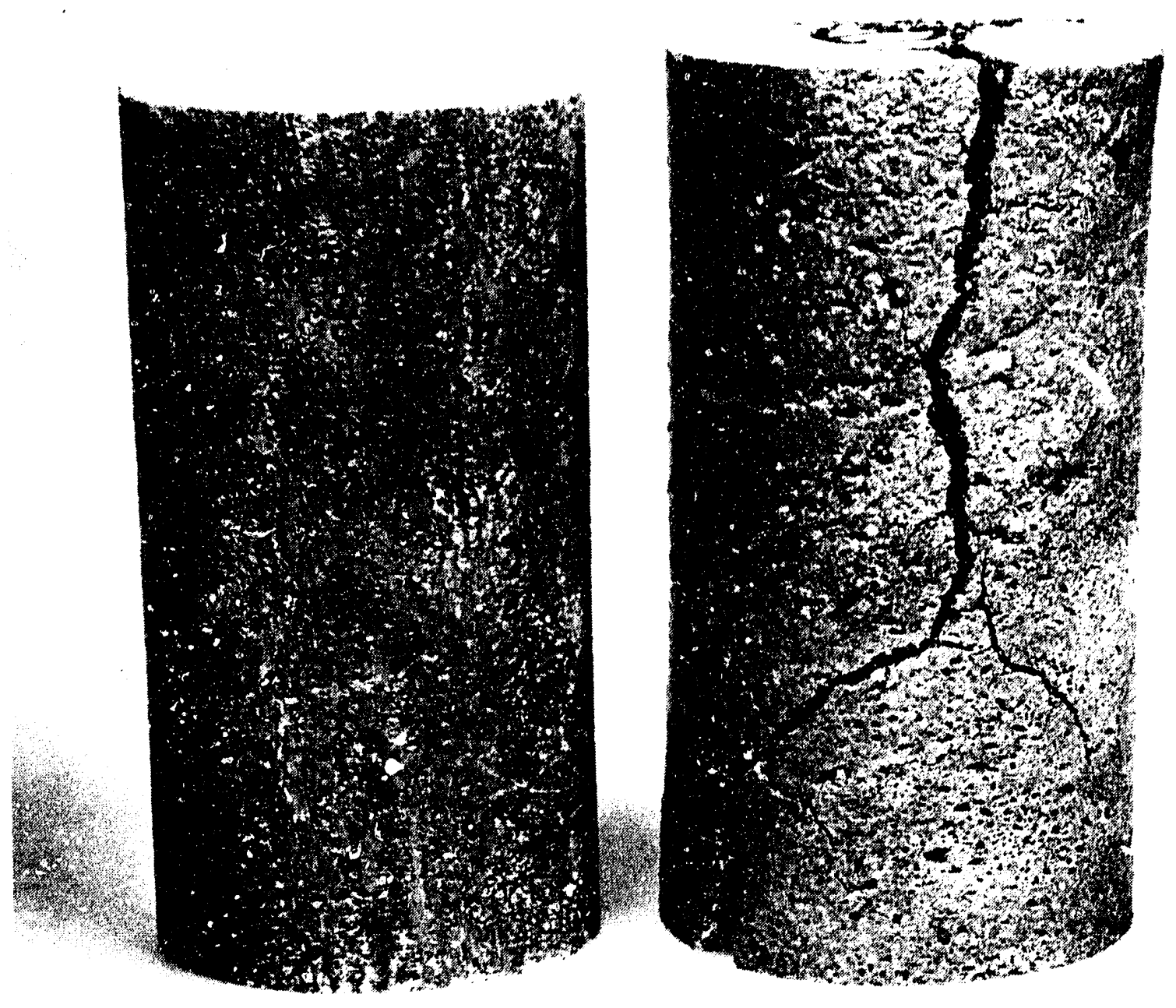

Figure 10 Photograph modified sulfur cement Hanford soil mortars after 5 days immersion in water. 


\subsection{Thermal Cycling}

Thermal cycling of materials can be useful not only to determine durability to temperature changes but also as a tool to indicated internal prestressing and as a comparative measure of quality. While a subterranean containment barrier for USTs is not expected to see freezing conditions (unless a cryogenic barrier is used as a secondary backup) thermal cycling was used as a qualitative yard stick. Thermal cycling causes expansion and contraction of the material thus fatiguing the sample. Materials that are highly prestressed or have low strength, especially tensile, will be more prone to damage from thermal cycling.

Six replicate samples of VES, PES, MSC, and $3 \mathrm{M} 4 \mathrm{R}$ soil mortars were tested in accordance to ASTM B-553[21] with modifications recommended by the Nuclear Regulatory Commission.[22] Cycling of the samples was performed using a microprocessor controlled environmental chamber capable of temperature ranges between 73 and $+200^{\circ} \mathrm{C} \pm 0.3^{\circ} \mathrm{C}$. The specimen were placed in the chamber and cycled between 40 and $+60^{\circ} \mathrm{C}$ for a total of 30 cycles, with each cycle lasting approximately 5 hours. A plot of temperature versus time for one cycle is given in Figure 11.

After cycling was complete, the samples were visually checked and measured. No visible effects were observed and no dimensional changes recorded for any of the soil mortars. The samples were then subjected to compressive strength testing and compared to baseline vaiues. UCS values for VES and $3 \mathrm{M} 4 \mathrm{R}$ mortar samples remained basically unchanged. PES samples gained $\sim 26 \%$ of their baseline strength after thermal cycling. This increase may be due to further crosslinking reactions induced by the higher temperatures in the thermal cycle. MSC samples were adversely effected by thermal cycling and lost an average of $51 \%$ of their baseline compressive strength. Data for USC is given in Table 6 and a graphical presentation of the results of thermal cycling is shown in Figure 12.

Table 6 Compressive Strengths of Soil Mortars After Thermal Cycling

\begin{tabular}{|l|c|c|c||}
\hline \hline Material & Post Cycling & std. dev. & $\%$ change \\
\hline \hline VES & $7560[52.1]$ & $239[1.65]$ & +9 \\
\hline 3M 4R & $3340[23.0]$ & $274[1.89]$ & -11 \\
\hline PES & $7390[51.0]$ & $262[1.81]$ & +4 \\
\hline MSC lot 5 & $2030[14.0]$ & $188[1.30]$ & -42 \\
\hline MSC lot 6 & $1700[11.7]$ & $120[0.83]$ & -60 \\
\hline
\end{tabular}




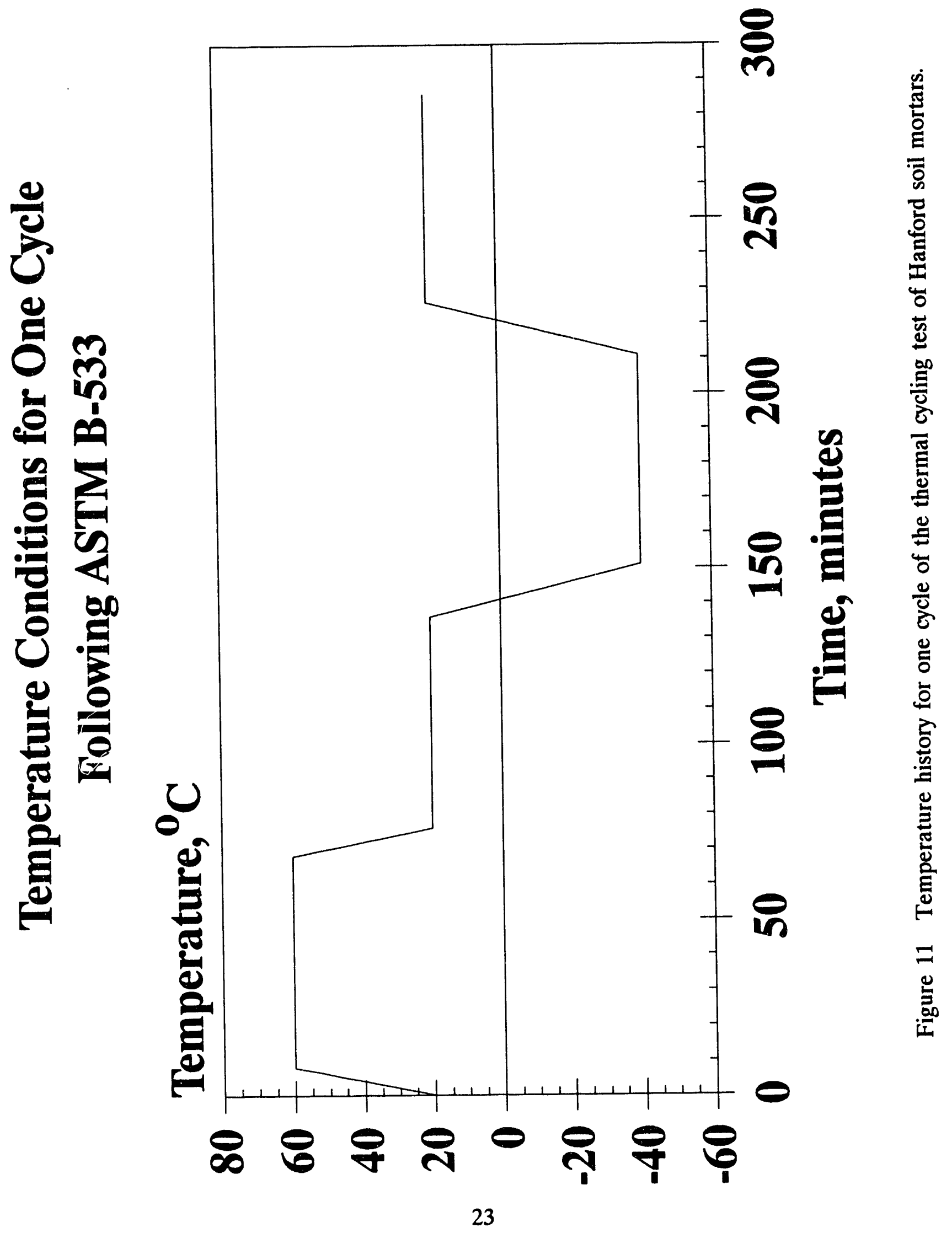




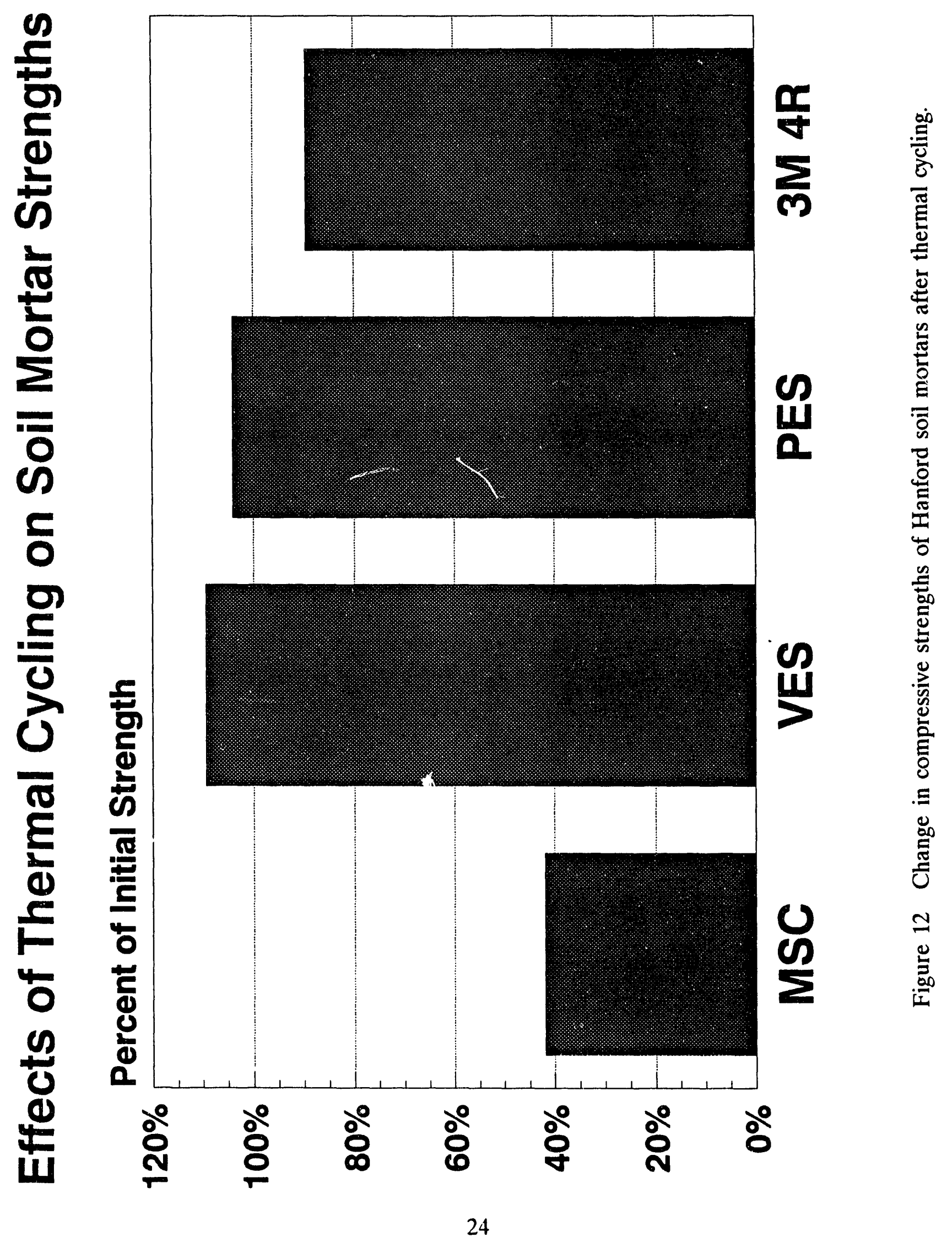




\subsection{Irradiation Stability}

The 106-C UST at the demonstration site is a high activity storage facility. The containment barrier should be expected to receive an appreciable radiation dose during the projected 25 year lifetime. The radiation fields in many of the USTs are stated to be in excess of $1000 \mathrm{rad} / \mathrm{hr} .[1,20,21]$ This translates to slightly more than $2 \times 10^{8}$ rad over 25 years for worst case tanks. The containment barrier will not see the full dose since the UST concrete and steel liner and surrounding soils will shield the barrier. In order to remain conservative, a total dose of $1 \times 10^{8}$ rads was chosen for testing purposes. Irradiation was performed in a Co-60 gamma facility at BNL. The dose rates ranged from $1 \times 10^{6}$ to $4 \times 10^{6} \mathrm{rad} / \mathrm{hr}$. After irradiation, the samples were visually inspected and measured for dimensional changes. The PES samples changed color from a white tinting to a beige to yellow after irradiation. No other visual or dimensional changes were observed. The samples were then destructively tested for compressive strength (ASTM D695). The results are given in Table 7 and shown graphically in Figure 13. The three thermoset binders all show significant strength increases after irradiation. This is a commonly observed phenomena attributable to additional cross-linking of the polymer chains. The polymers will continue to crosslink due to the energy input of the irradiation. This will continue only to a point and then the energy from irradiation will begin to break bonds and a gradual decrease will be observed. The MSC showed mixed inconclusive results. Lot 3 (5 samples) shows a 20 percent strength loss with a baseline standard deviation of 8 percent. Lot 4 ( 3 samples) showed a $6 \%$ increase that is within one standard deviation for the lot.

Table 7 Compressive Strength of Irradiated Soil Mortar Composites

\begin{tabular}{||l|c|c|c|}
\hline \multicolumn{1}{|c|}{ Material } & $\begin{array}{l}\text { Post Irradiation } \\
\text { psi }[\mathrm{MPa}]\end{array}$ & std. dev. & \% change \\
\hline VES & $9080[62.6]$ & $357[2.46]$ & +31 \\
\hline 3M 4R & $5840[40.3]$ & $860[5.93]$ & +57 \\
\hline PES & $7840[54.1]$ & $239[1.65]$ & +10 \\
\hline MSC lot 3 & $3600[24.8]$ & $505[3.48]$ & -20 \\
\hline MSC lot 4 & $3760[25.9]$ & $572[3.94]$ & +6 \\
\hline
\end{tabular}

${ }^{\text {a }}$ total dose of $10^{8}$ rads. 


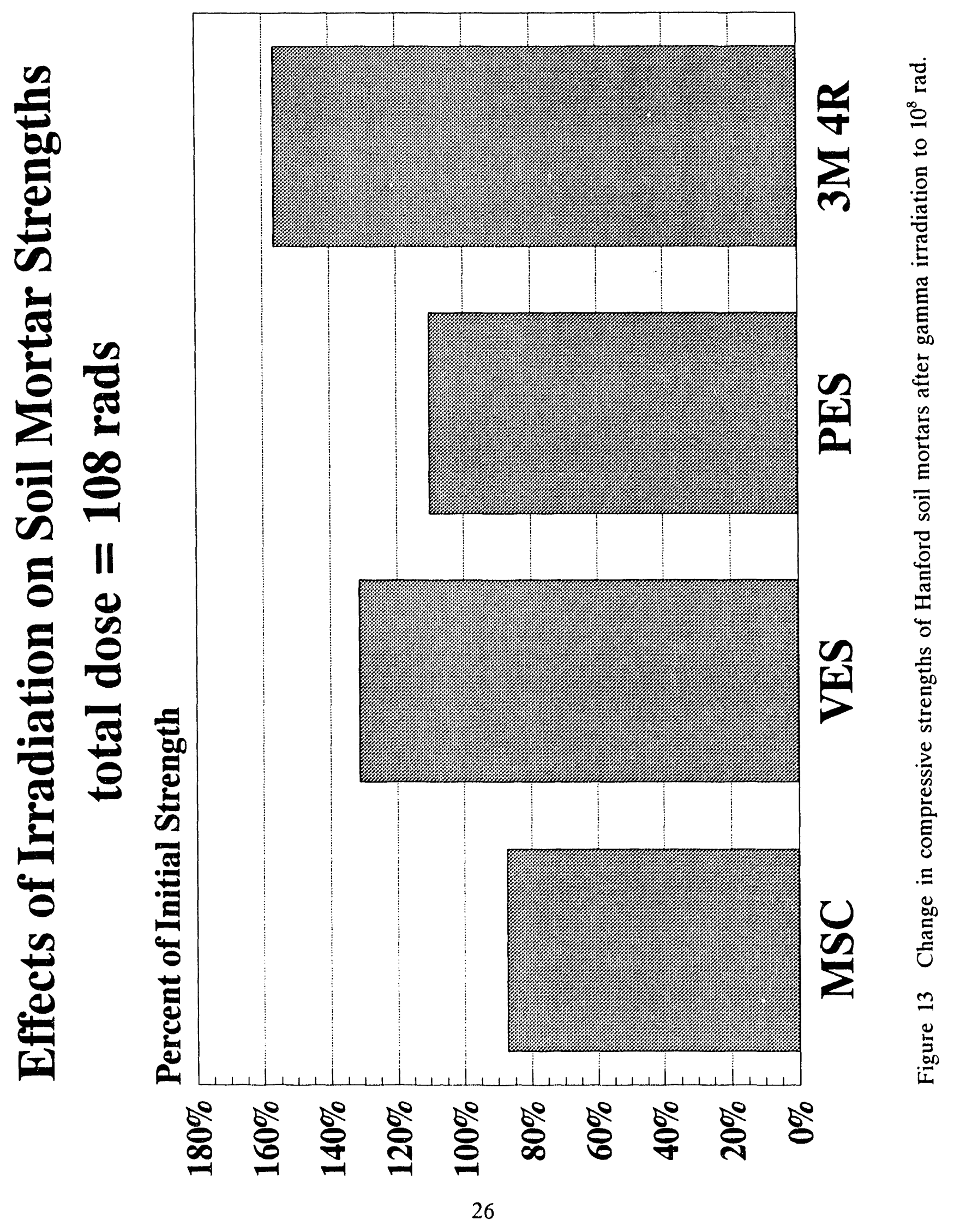




\subsection{Wet-Dry Cycling}

The Hanford tank farm is located in a semi-arid region. The soil moisture content is fairly dry and as stated earlier ranges between 1 and $3 \%$. Assuming little or no tank leakage, the barrier will be under dry conditions most of the time. There are times when precipitation percolates the ground and recharges the aquifer. During these times the barrier will be under saturated conditions. Wet-dry cycling is known to have a severe impact on construction materials such as hydraulic cements. Replicate samples of VES, 3M 4R, and PES soil mortars were subjected to wet-dry cycling following ASTM D-4843.[23] [MSC was excluded based on water immersion results.] The test cycle samples from $60^{\circ} \mathrm{C}$ dry to $20^{\circ} \mathrm{C}$ wet, twelve times. The ASTM test calls for evaporating the water after each wet cycle and weighing the residue left in the beaker. The samples were wet cycled in the same beaker for each cycle reusing the water (additional water was added to replenish loses from evaporation). At the end of the final cycle the water was evaporated and the residue weight recorded. The wet samples were towel dried and weighed after each cycle. The dry cycle samples were weighed directly (Table 8 ). The weight histories of each sample are plotted in Figures 14, 16, and 18. The "end" weight represents the weight of the samples after the seven day $40 \%$ humidity conditioning. In addition to the test method, samples were compression tested after the final cycle to determine mechanical integrity. Upon completion of wet-dry cycling the samples were conditioned at $40 \%$ relative humidity for seven days and then tested for UCS (ASTM D-695).

None of the samples showed any visible degradation after 12 cycles. Final weight changes were minimal and the averages are given in Table 8 . The table also gives values for the average fluctuation in weight going from the saturated to the dry condition. To illustrate the small weight changes observed for all the polymer mortars, the dry cycle weights have been plotted as percent of initial dry weight versus cycle number (Figures 15 , 17, and 19). The scale spans less than $1.5 \%$ for all polymer soil mortars tested. The polymers proved to be extremely resistant to wet-dry cycling. This was substantiated by performing compressive strength testing of the cycled samples. The values of UCS given in Table 9 show no strength loses for any binder system. Instead, all the binders showed slight strength increases (see also Figure 20). 
Table 8 Weight Changes of Samples Subjected to Wet-Dry Cyclinga

\begin{tabular}{|c|c|c|c|}
\hline Material & VES & $3 \mathrm{M} 4 \mathrm{R}$ & PES \\
\hline $\begin{array}{l}\text { Weight } \\
\text { Before }^{b}\end{array}$ & 193.68 & 192.22 & 182.28 \\
\hline Weight After ${ }^{b}$ & 192.33 & 194.14 & 180.00 \\
\hline$\%$ Change $^{\mathrm{b}}$ & -0.7 & +1.0 & -1.2 \\
\hline $\begin{array}{l}\text { Initial Dry } \\
\text { Weight }\end{array}$ & 192.12 & 190.20 & 179.68 \\
\hline $\begin{array}{l}\text { Final Dry } \\
\text { Weight }\end{array}$ & 190.55 & 191.14 & 178.41 \\
\hline$\%$ Change & -0.8 & +0.5 & -0.7 \\
\hline $\begin{array}{l}\text { Initial Wet }{ }^{c} \\
\text { Weight }\end{array}$ & 195.32 & 194.51 & 182.73 \\
\hline $\begin{array}{l}\text { Final Wet }{ }^{d} \\
\text { Weight }\end{array}$ & 194.35 & 197.46 & 181.75 \\
\hline$\%$ Change & -0.5 & +1.5 & -0.5 \\
\hline $\begin{array}{l}\text { avg. } \\
\text { fluctuation per } \\
\text { cycle }\end{array}$ & 3.52 & 5.36 & 3.28 \\
\hline residue & 0.15 & 0.15 & 0.06 \\
\hline
\end{tabular}

(a) values are in grams and are composites of six replicates

(b) measured at $40 \% \mathrm{RH}$,

(c) from first cycle,

(d) from last cycle

Table 9 Compressive Strengths of Soil Mortar Samples After Wet-Dry Cycling

\begin{tabular}{||l|c|c|c||}
\hline \multicolumn{1}{|c|}{ Materials } & $\begin{array}{c}\text { UCS after wet-dry } \\
\text { cycling, psi [MPa] }\end{array}$ & std. dev. & \% change \\
\hline \hline VES & $7630[52.6]$ & $388[2.68]$ & +10 \\
\hline 3M 4R & $4930[34.0]$ & $744[5.13]$ & +32 \\
\hline PES & $8390[57.8]$ & $787[5.43]$ & +18 \\
\hline
\end{tabular}




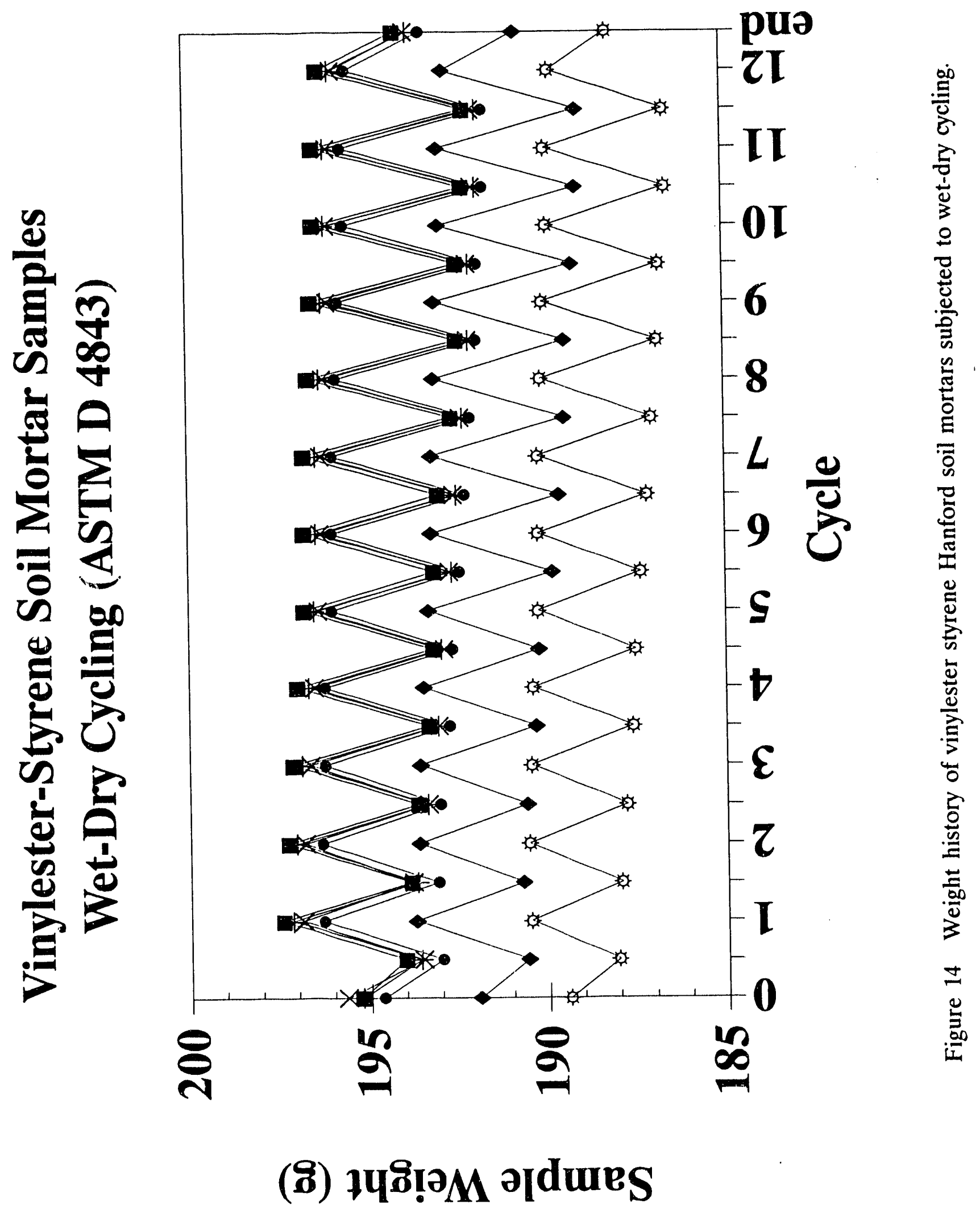




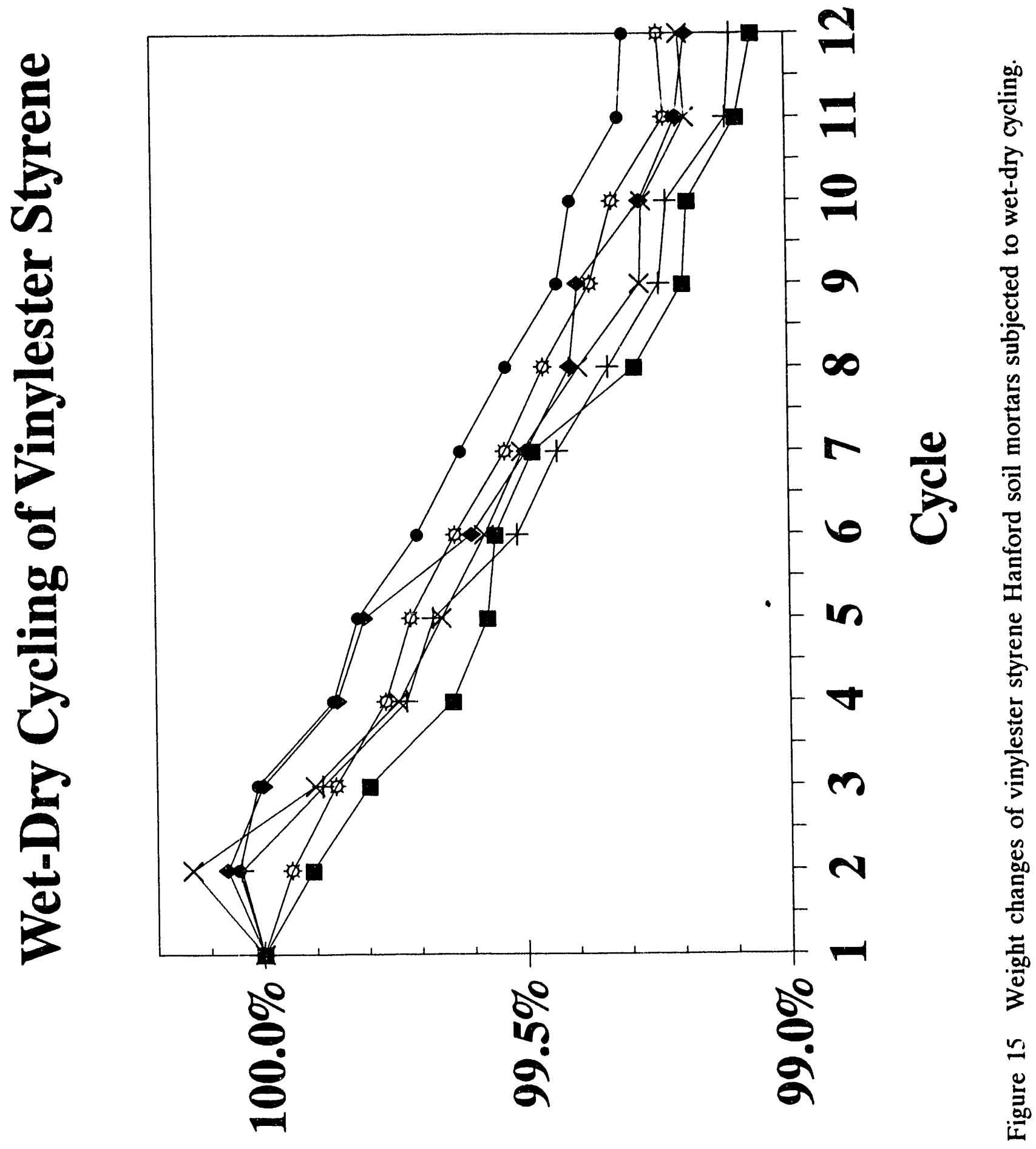

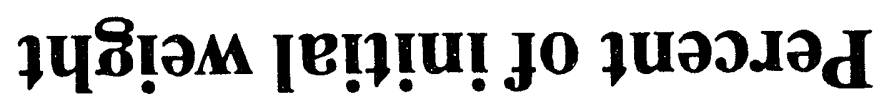




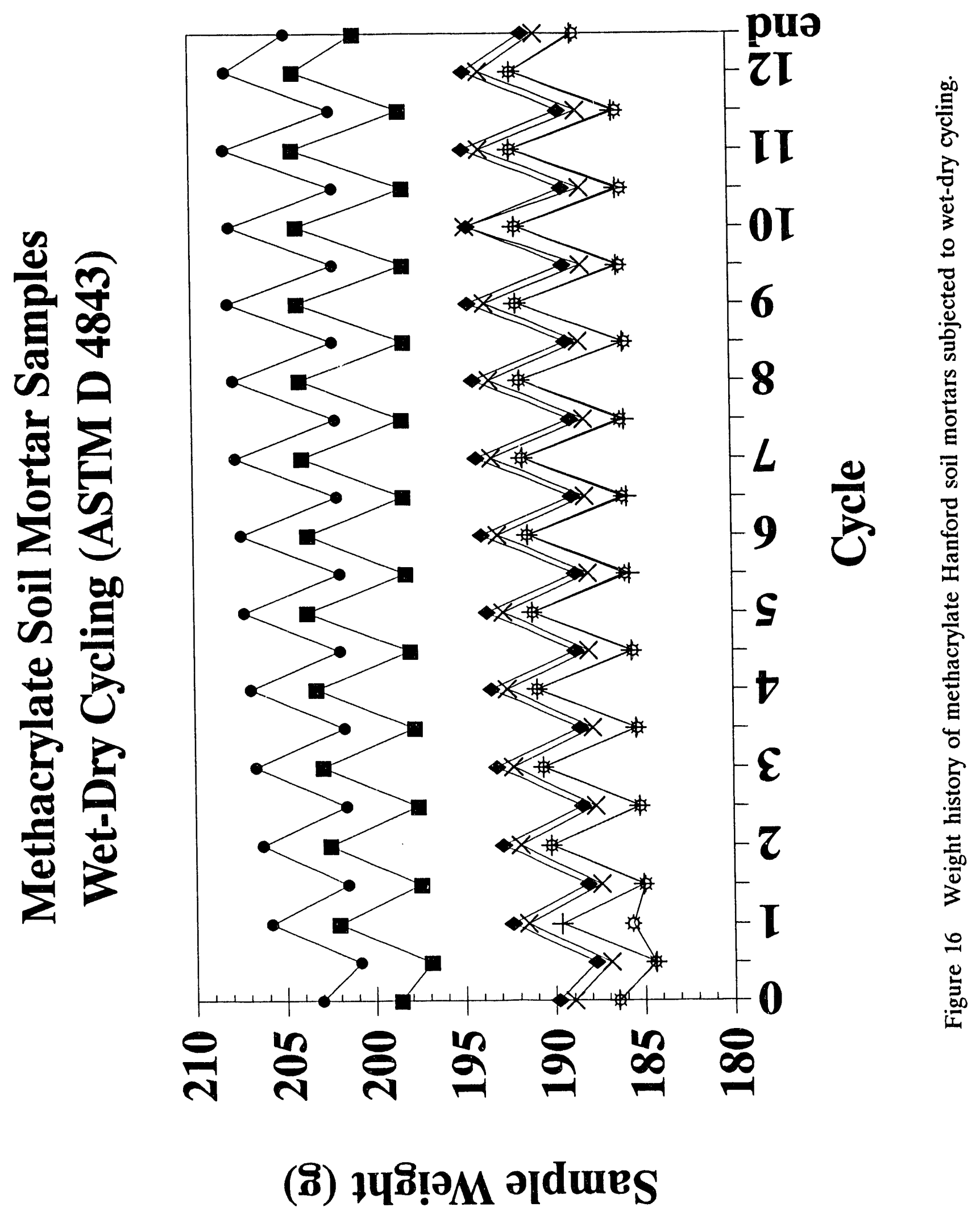



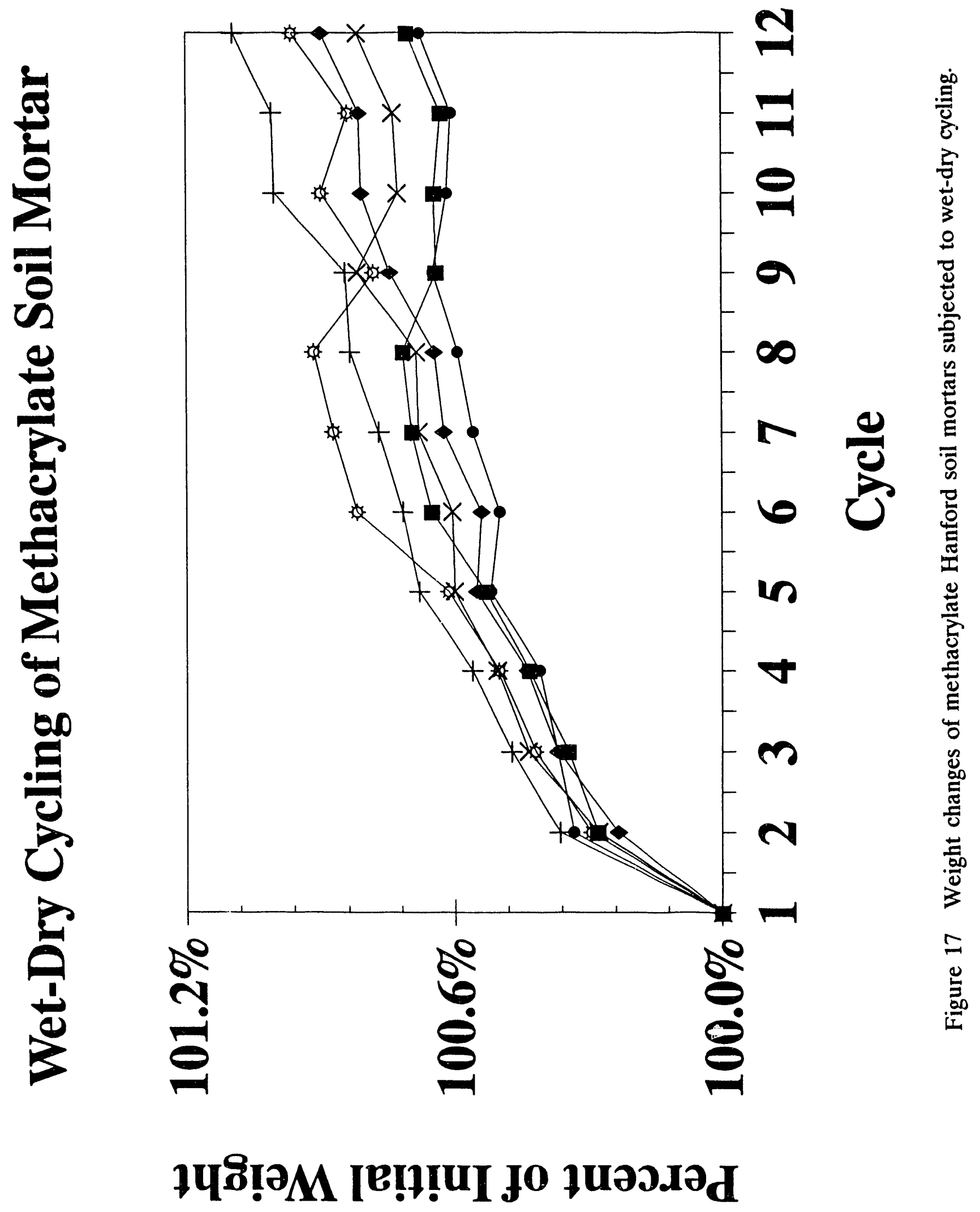


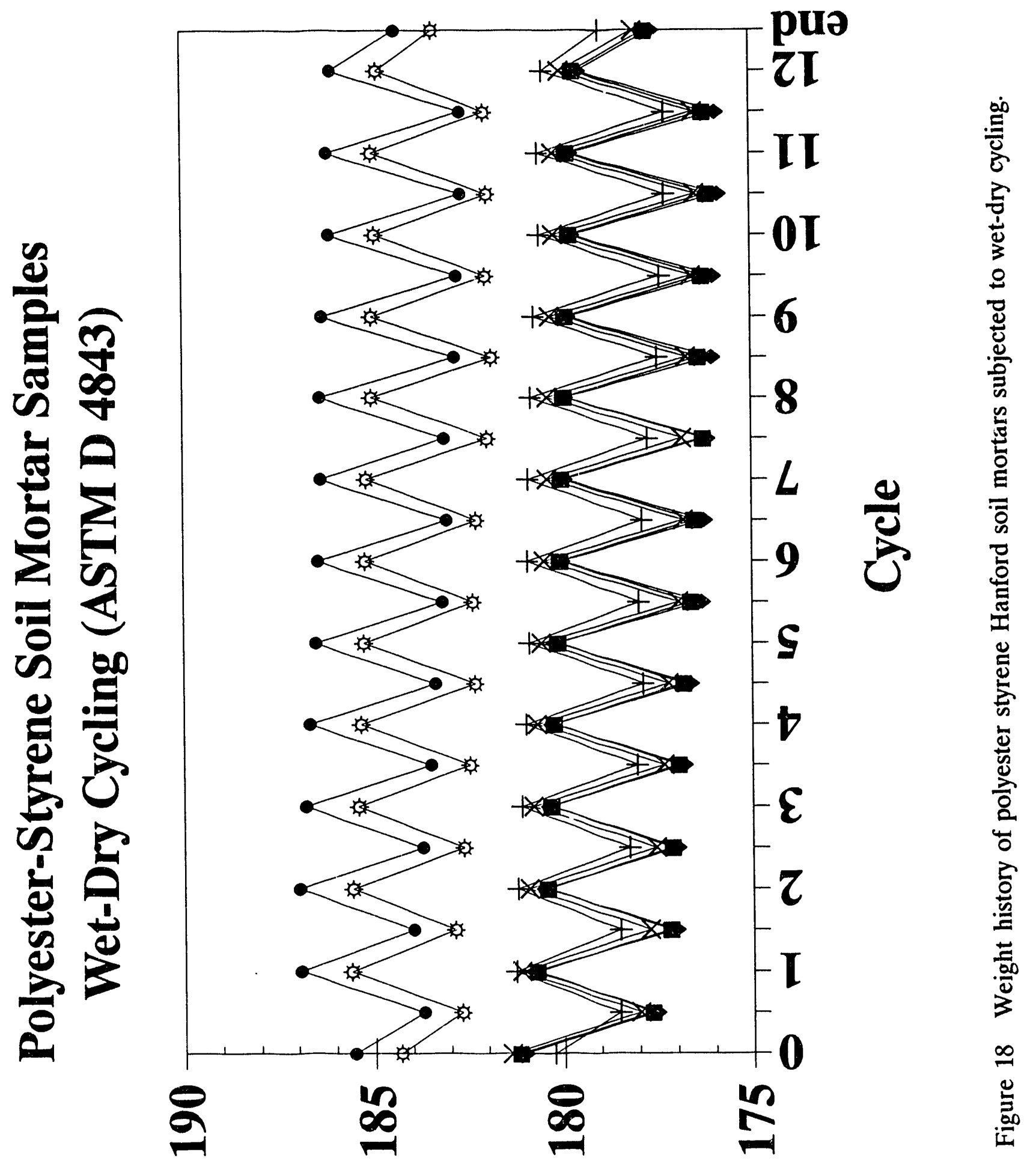

(8) 148 เి๋ 


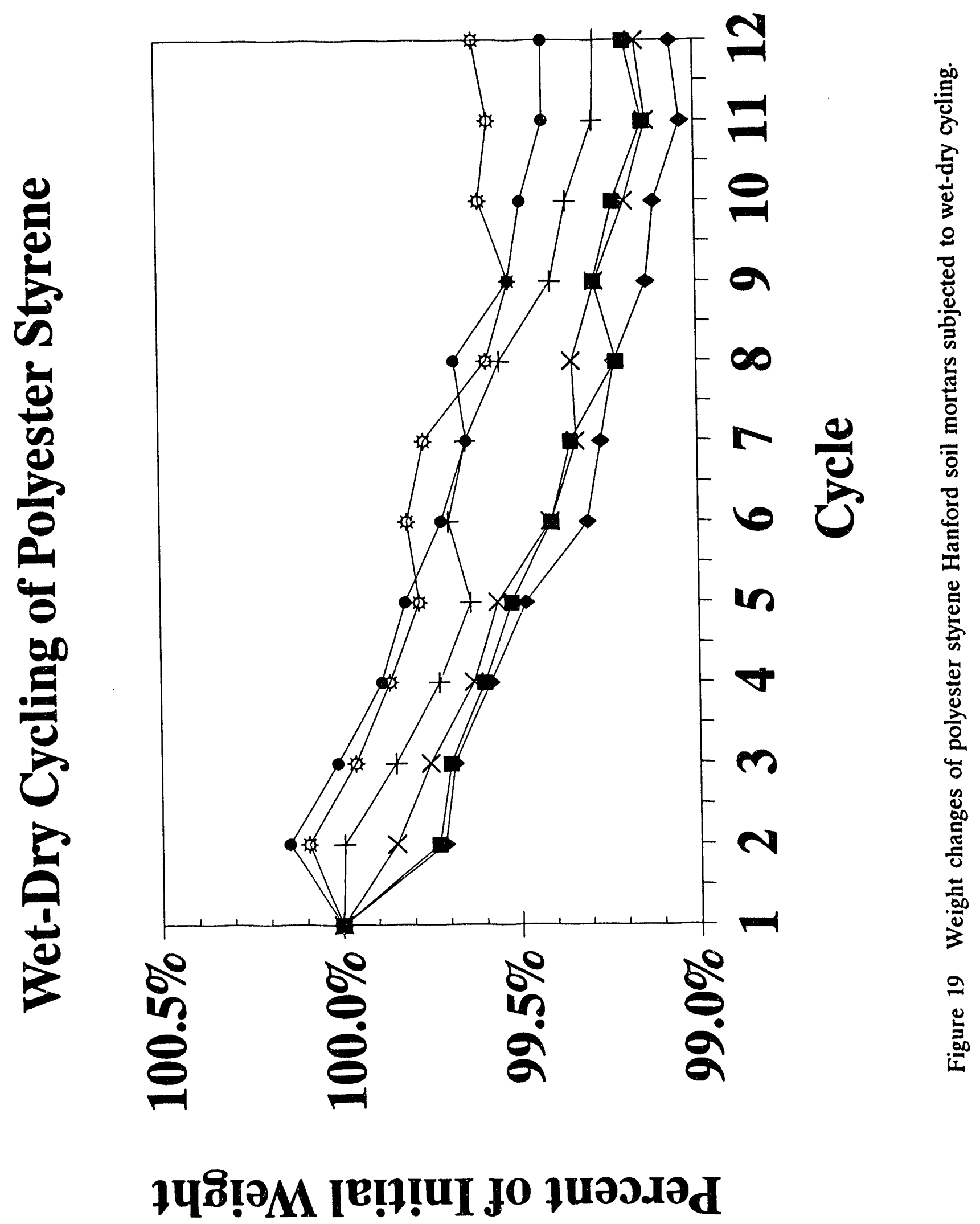




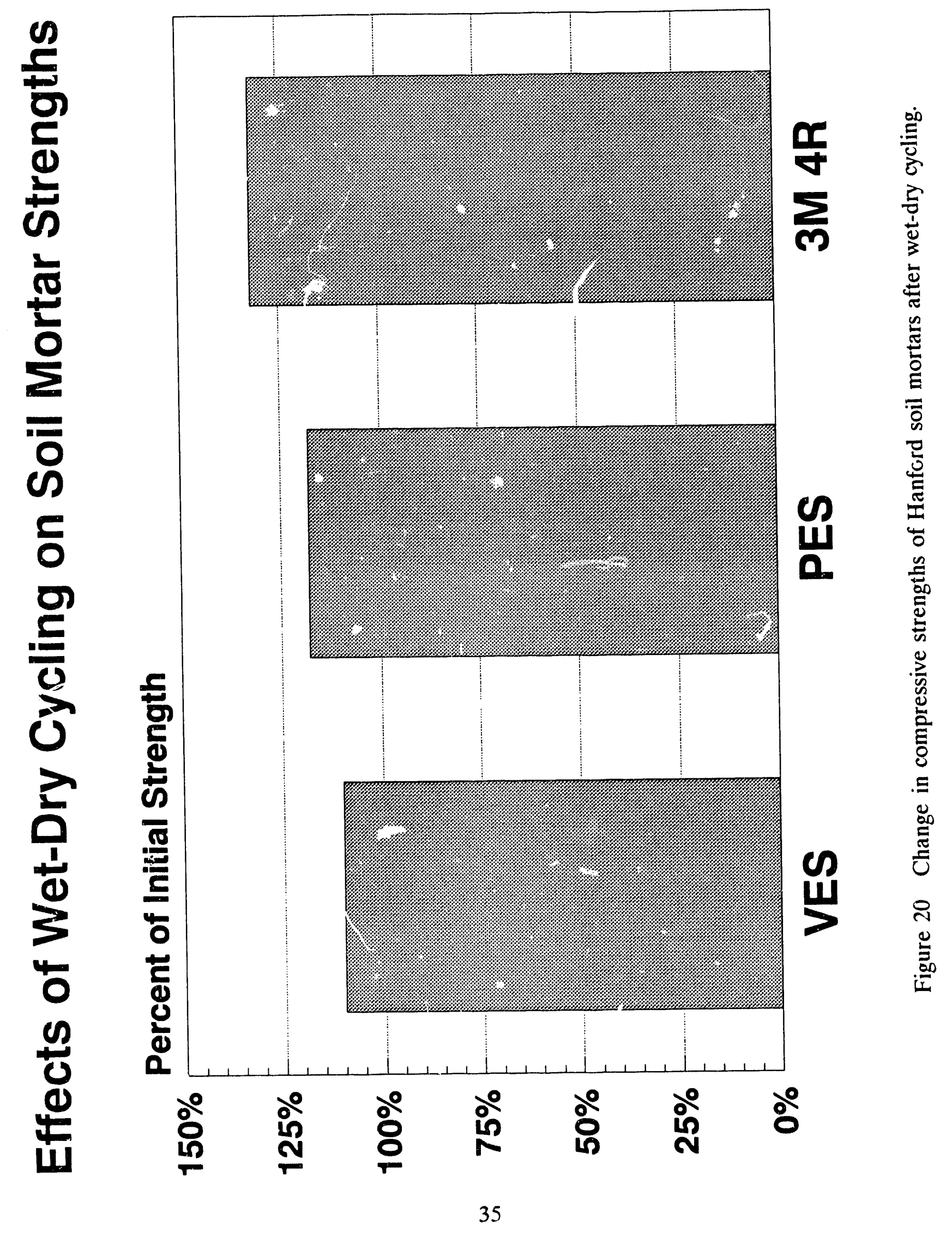




\subsection{Hot Nitrate Brine Immersion}

In the event of leakage from USTs, the barrier will presumably be exposed to the supernatant from the tank. The supernatants in most of the USTs are nitrate-nitrite salt solutions. For the demonstration tank, the composition of the supernatant is given in Table 10.[2] The liquid may also be at elevated temperature due to the heat production from radionuclide decay. To determine the durability of the soil-polymer composites, in this environment, samples were subjected to immersion in a hot surrogate nitrate brine. The brine was $50 \%$ solids usi ig salts in the proportions taken from Table 10. The temperature of $70^{\circ} \mathrm{C}$ was taken as the average tank temperature of the 11 high heat $(>40,000 \mathrm{Btu} / \mathrm{hr})$ tanks at Hanford.[1] Twelve samples of VES, 3M 4R, and PES soil mortars were immersed in the brine and placed in an environmental chamber at $70^{\circ} \mathrm{C}$. [MSC was excluded based on water immersion results.] The samples were inspected routinely for cracking and/or spalling. At 30 day intervals three samples of each soil-mortar composite were removed for visual and destructive testing to determine sample integrity. Salt crystals formed on the sides of the samples after $\sim 1$ week with no signs of degradation. Figure 21 shows photographs of the samples as they were removed from the brine ( 30 days). The samples were scrubbed clean with water and steel wool to remove the crystal formations. It should be noted that the crystals were most heavy on the $3 \mathrm{M} 4 \mathrm{R}$ mortar followed by the PES and VES. The crystals showed a slight orange to brown coloration which indicates probable interaction between the iron in the soil and the brine. [None of the surrogate brine salts were originally colored.] After cleaning, the samples were inspected for cracking and spalling. All samples appeared sound. The specimens were then conditionea at $40 \% \mathrm{RH}$ for seven days and tested for compressive strength. The results for up to 60 days exposure, given in Table 11 (also Figure 22), show no loss in integrity for any of the composites.

Table 10 Estimated Chemical Composition of Supernatant for Single-Shell Tanks[1]

\begin{tabular}{|l|l|}
\hline \multicolumn{1}{|c|}{ Chemical } & Dry Weight \% \\
\hline \hline $\mathrm{NaNO}_{3}$ & 34.7 \\
\hline $\mathrm{NaNO}_{2}$ & 26.4 \\
\hline $\mathrm{Na}_{2} \mathrm{CO}_{3}$ & 1.0 \\
\hline $\mathrm{NaOH}$ & 10.4 \\
\hline $\mathrm{NaAlO}$ & 20.9 \\
\hline $\mathrm{Na}_{3} \mathrm{PO}_{4}$ & 3.8 \\
\hline Organic & 2.8 \\
\hline
\end{tabular}




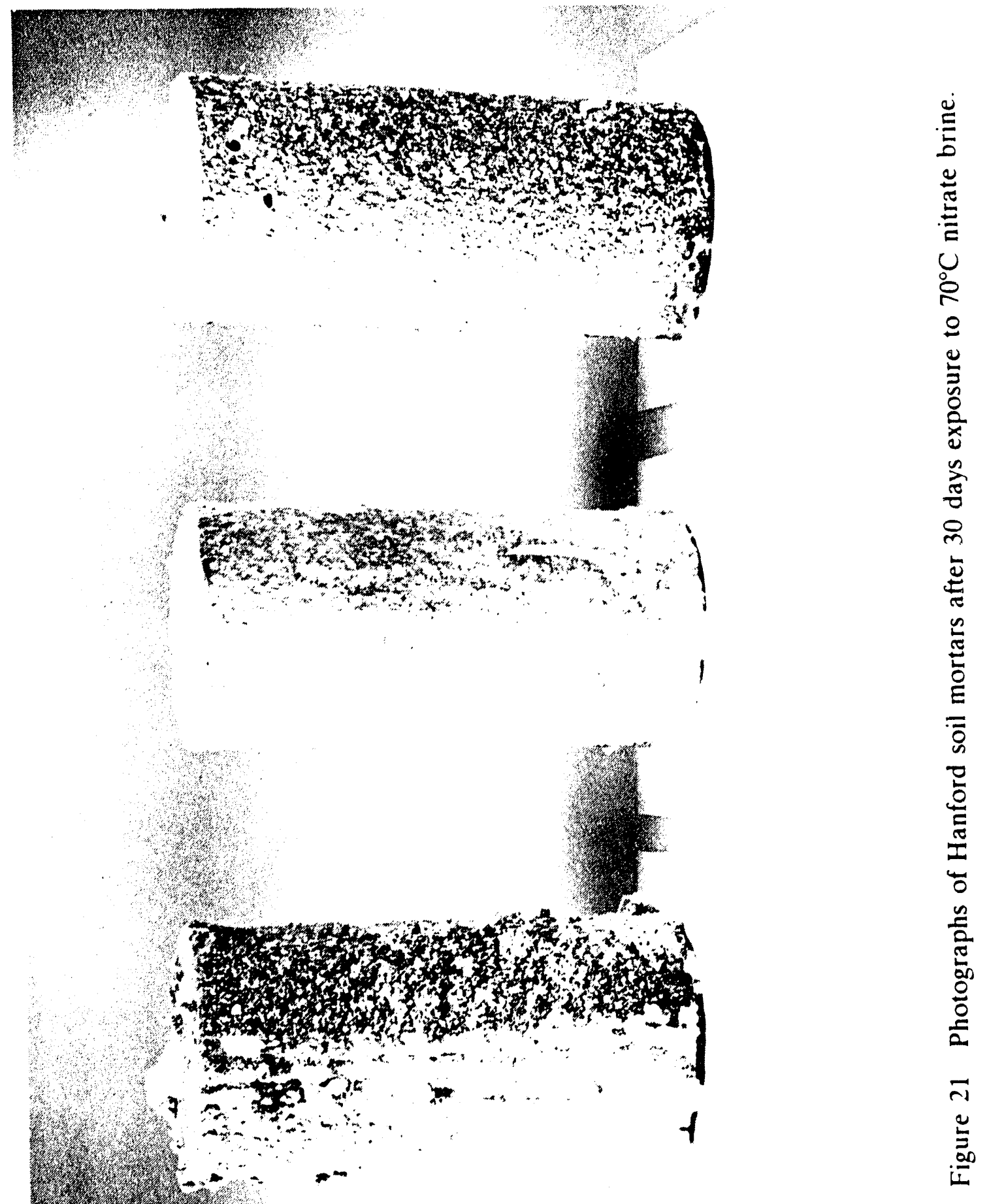



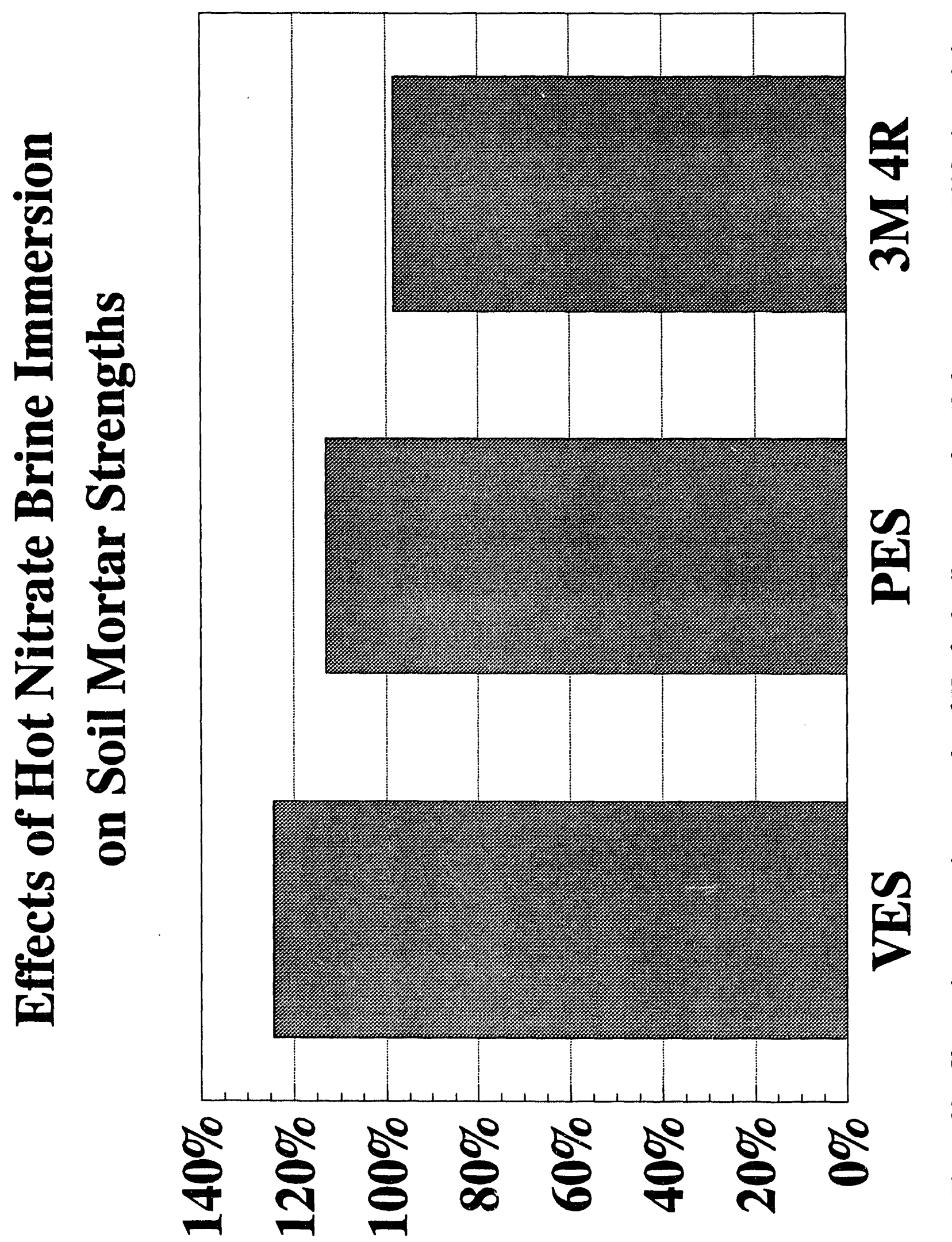

.

䒕

$\stackrel{0}{\circ}$

용

는

ํㅗㅇ

尔

8

这

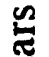

त)

\%

훙

ב

ర

告

紊

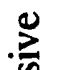

C2

(r) हू유

.E

慈

ส

㫕 
Table 11 Compressive Strengths of Soil Mortars After Exposure to $70^{\circ} \mathrm{C}$ Nitrate Brine

\begin{tabular}{|c|c|c|c|c|}
\hline Material & $\begin{array}{l}\text { Exposure } \\
\text { Time (d) }\end{array}$ & $\begin{array}{c}\text { UCS } \\
\text { (ASTM D-695) }\end{array}$ & std. dev. & $\%$ change \\
\hline VES & \multirow{3}{*}{30} & 8600 [59.3] & $162[1.12]$ & +24 \\
\hline PES & & 8040 [55.4] & $345[2.38]$ & +13 \\
\hline $3 \mathrm{M} 4 \mathrm{R}$ & & $3690[25.4]$ & $291[2.01]$ & -2 \\
\hline VES & \multirow{3}{*}{60} & 9240 [63.7] & $211[1.45]$ & +34 \\
\hline PES & & $8090[55.8]$ & 515 [3.55] & +14 \\
\hline $3 \mathrm{M} 4 \mathrm{R}$ & & $3550[24.5]$ & $362[2.50]$ & -5 \\
\hline
\end{tabular}

\subsection{Hydraulic Conductivity}

One of the most important performance considerations for a containment barrier is the rate that liquids will penetrate the barrier. Hydraulic conductivity is a direct measure of the ability of the barrier to retain leakage from the UST. The hydraulic conductivities of samples of VES, PES, and 3M 4R soil mortars were measured following ASTM D-. 5084.[24] Measurements were made using a flexible wall permeameter. The permeant was deaired tap water having an electrical conductivity of $120 \mu$ mhos. Test samples were $3.8 \mathrm{~cm}$ diameter cylinders with a height of $3.0 \mathrm{~cm}$. Samples were preconditioned in tap water for several days to induce saturation. The test specimens were then placed in the permeameter cell and sealed using a latex membrane and a 10 psi differential cell pressure. Back pressuring was used to ascomplish full saturation of the samples. Full saturation was determined by measuring the compression B value using ASTM D-4767-(88).[25] The pressure required to bring about a compression $B$ value of .95 or greater varied with the mortars, VES samples required 10 psi, PES samples 30 psi, and $3 \mathrm{M} 4 \mathrm{R}$ mortars 20 psi. Measurements were made at three different pressure differentials to assure that Darcy's Law behavior was obeyed. After allowing for stabilization, permeabilities were calculated for three consecutive 24 hour readings. The results are given in Table 12. 
Table 12 Hydraulic Conductivity of Hanford Soil Mortars

\begin{tabular}{|c|c|c|c|c|}
\hline \multicolumn{5}{|c|}{ Hydraulic Conductivity of Polymer Soil Mortars (M/s x 10 $0^{-12}$ ) } \\
\hline$\Delta \mathrm{P}, \mathrm{psi}$ & interval & VES & PES & $3 \mathrm{M} 4 \mathrm{R}$ \\
\hline \multirow{3}{*}{30} & 1 & 8.3 & 2.8 & 48 \\
\hline & 2 & 8.0 & 2.7 & 37 \\
\hline & 3 & 6.7 & 2.8 & 37 \\
\hline \multirow{3}{*}{20} & 1 & 5.8 & 1.7 & 36 \\
\hline & 2 & 6.2 & 1.5 & 47 \\
\hline & 3 & 5.8 & 1.5 & 38 \\
\hline \multirow{3}{*}{10} & 1 & 6.2 & 1.5 & 37 \\
\hline & 2 & 5.5 & 3.0 & 42 \\
\hline & 3 & 7.8 & 2.4 & 40 \\
\hline Average & -- & 6.7 & 2.2 & 40 \\
\hline
\end{tabular}




\section{CONCLUSIONS}

Polymer concrete soil composites appear to be well suited to conditions expected to be prevalent at the Hanford UST site. Short term testing in severe conditions have shown soil mortars made with vinylester styrene, polyester styrene, and a high molecular weight methacrylate to be extremely durable. From laboratory testing the following observations were made:

1. Sufficient strengths are easily achieved with polymer-soil composites. The order of strengths were PES > VES $>$ MSC $>3 \mathrm{M} 4 \mathrm{R}$.

2. VES, PES, and $3 M 4 R$ have surpassed 90 days water immersion with no loss in integrity.

3. MSC failed in water immersion after 3-5 days exposure. This is attributed to some expansive quality of the Hanford soil.

4. VES and PES samples survived thermal cycling with no strength losses. 3M 4R soil mortars showed an 11\% strength loss against a baseline standard deviation of $10 \%$. MSC failed to retain a reasonable amount of strength, showing losses of $40-60 \%$ of original strength.

5. The thermosetting polymers showed strength gains averaging $32 \%$ after $10^{8}$ rads irradiation from a gamma source. The strength gains are attributed to additional crosslinking of the polymer. Results from MSC were inconclusive. One lot of three samples showed a $6 \%$ strength gain with a baseline standard deviation of $6 \%$. The second lot (5 samples) had a $20 \%$ loss with a baseline standard deviation of $8 \%$.

6. VES, PES, and $3 \mathrm{M} 4 \mathrm{R}$ soil mortars were subjected to wet-dry cycling with no detrimental effects. The average weight changes were -0.7 , 1.2 , and $+1.0 \%$ for VES, PES, and $3 \mathrm{M} 4 \mathrm{R}$ respectively. No strength loss occurred for any binder, with $3 \mathrm{M} 4 \mathrm{R}$ and PES soil mortars showing modest strength gains.

7. VES, PES, and $3 \mathrm{M} 4 \mathrm{R}$ withstood 60 days immersion in $70^{\circ} \mathrm{C}$ concentrated nitrate brine with no detrimental effects. The brine is a surrogate for the Hanford UST supernatant and is an aggressive media. No strength losses were recorded with modest strength increases for VES and PES samples. 
8. Soil mortar hydraulic conductivities on the order of $5 \times 10^{-12} \mathrm{M} / \mathrm{s}$ are achievable. VES samples averaged $6.7 \times 10^{-12} \mathrm{M} / \mathrm{s}, \mathrm{PES}$ averaged 2.2 $\times 10^{-12} \mathrm{M} / \mathrm{s}$, and $3 \mathrm{M} 4 \mathrm{R}$ samples averaged $40 \times 10^{-12} \mathrm{M} / \mathrm{s}$.

9. Polymer grouts having a wide range of viscosities $(300,100$, and $3 \mathrm{cps}$ for PES, VES, and $3 \mathrm{M} 4 \mathrm{R}$, respectively) have been demonstrated to have desirable qualities for a subterranean containment barrier. The resin characteristics should allow these materials to be used in a wide range of soil types and conditions. 


\section{REFERENCES}

1. Rouse, J.K., et al, Underground Storage Tank - Integrated Demonstration Functional Requirements, Westinghouse Hanford Company, Richland, Washington, 1992, WHC-EP-0566 Draft

2. Interim Subsurface Barrier Technologies Workshop Report, prepared by Bovay Northwest Inc., Prepared for Westinghouse Hanford Company, September 10, 1992.

3. Franz, E.M., Heiser, J.H., and Colombo, P., Immobilization of Sodium Nitrate Waste with Polymers, Topical Report, Brookhaven National Laboratory, April 1990, BNL-52081.

4. Dow Chemical Company, The Dow System for Solidification of Low-Level Radioactive Waste From Nuclear Power Plants, Topical Report, DNS-RSS-001-NPA, The Dow Chemical Company, Midland, Michigan, March 1978.

5. Williamson, A.S., and A. Husian, "A Plant for Immobilizing Low-Level Aqueous Waste in Water-Extendible Polymer," International Topical Meeting, Niagara Falls, NY, September 1986.

6. Vipulanandan, C., and Krishnan, S., "Solidification/Stabilization of Phenolic Waste with Cementitous and Polymeric Materials", 2nd Annual Symposium on Solidification/Stabilization - Mechanisms \& Applications, Gulf Coast Hazardous Substance Research Center, Beaumont, Texas, February 15-16, 1990.

7. "Acid-Proof, Salt Resistant Chempruf Sulphur Concrete", 4K A/S, Copenhagen, available through the Sulfur Institute, Washington, D.C.

8. Kalb, P.D., Heiser, J.H., and Colombo, P., Modified Sulfur Cement Encapsulation of Mixed Waste Contaminated Incinerator Fly Ash, Waste Management Journal, Vol 11, No. 3, 1991, Pergamon Press, NY.

9. Heiser, J.H., Franz, E.M., and Colombo, P., "A Process for Solidifying Sodium Nitrate Waste in Polyethylene", Environmental Aspects of Stabilization and Solidification of Hazardous and Radioactive Wastes, ASTM STP 1O33, American Society for Testing and Materials, Philadelphia, 1989, pp 53-62.

10. Moriyama, N., et al, "Incorporation of an Evaporator Concentrate in Polyethylene for a BWR," Nuclear and Chemical Waste Management 3, 1982. 
11. Neilson, R.M., and Colombo, P., Waste Form Development Program, Annual Progress Report, September 1982, BNL-51614, Brookhaven National Laboratory, Upton, New York.

12. Form No. 296-320-1290X SMG, Chemical Resistance and Engineering Guide, Derakane Resins, Dow Plastics, The Dow Chemical Company, Midland, Michigan.

13. Kukacka, L.E., and Sugama, T., Furfuryl Alcohol Polymer Concretes for use in AllWeather Repairs of Concrete and Asphalt Surfaces, Brookhaven National Laboratory, 1985, BNL-36465.

14. Bodocsi, A. and Bowers, M.T., "Permeability of Acrylate, Urethane, and Silicate Grouted Sands with Chemicals", Journal of Geotechnical Engineering, Vol. 117, No. 8, Aug 1991, pp 1227-1244.

15. Karol, R. K., Chemical Grouting, Second edition, Marcel Dekker, Inc., N.Y.,1990.

16. McBee, W.C., and Sullivan, T.A., Development of Specialized Sulfur Concretes, U.S. Department of the Interior, Bureau of Mines, 1979.

17. Kalb, P.E., Heiser J.H., and Colombo, P., Modified Sulfur Cement Encapsulation of Mixed Waste Contaminated Incinerator Fly Ash, Waste Management "Incineration '90" issue.

18. ASTM D-4972 (89), "Standard Test Method for pH of Soils", American Society for Testing and Materials, Philadelphia, PA.

19. ASTM D-695 (88), "Compressive Properties of Rigid Plastics", American Society for Testing and Materials, Philadelphia, PA.

20. AC-400 Chemical Grout (Added Strength), Product Specification Sheet, Geochemical Corporation, Ridgewood, NJ, 1992.

21. ASTM B-553 (79), "Standard Test Method for Thermal Cycling of Electroplated Plastics", American Society for Testing and Materials, Philadelphia, PA.

22. U.S. NRC, "Technical Position on Waste Forms, Revision 1", Final Waste Classification and Waste Form Technical Position Papers, U.S. Nuclear Regulatory Commission, Low-Level Waste Licensing Branch, Washington, D.C., January 1991.

23. ASTM D-4843 (88) "Wetting and Drying of Solid Wastes", American Society for Testing and Materials, Philadelphia, PA. 
24. ASTM D-5084 (90) "Measurement of Hydraulic Conductivity of Saturated Porous Materials Using A Flexible Wall Permeameter", American Society for Testing and Materials, Philadelphia, PA.

25. ASTM D-4767, "Standard Test Method for Consolidated Undrained Triaxial Compression Test on Cohesive Soils", (1988), American Society for Testing and Materials, Philadelphia, PA. 

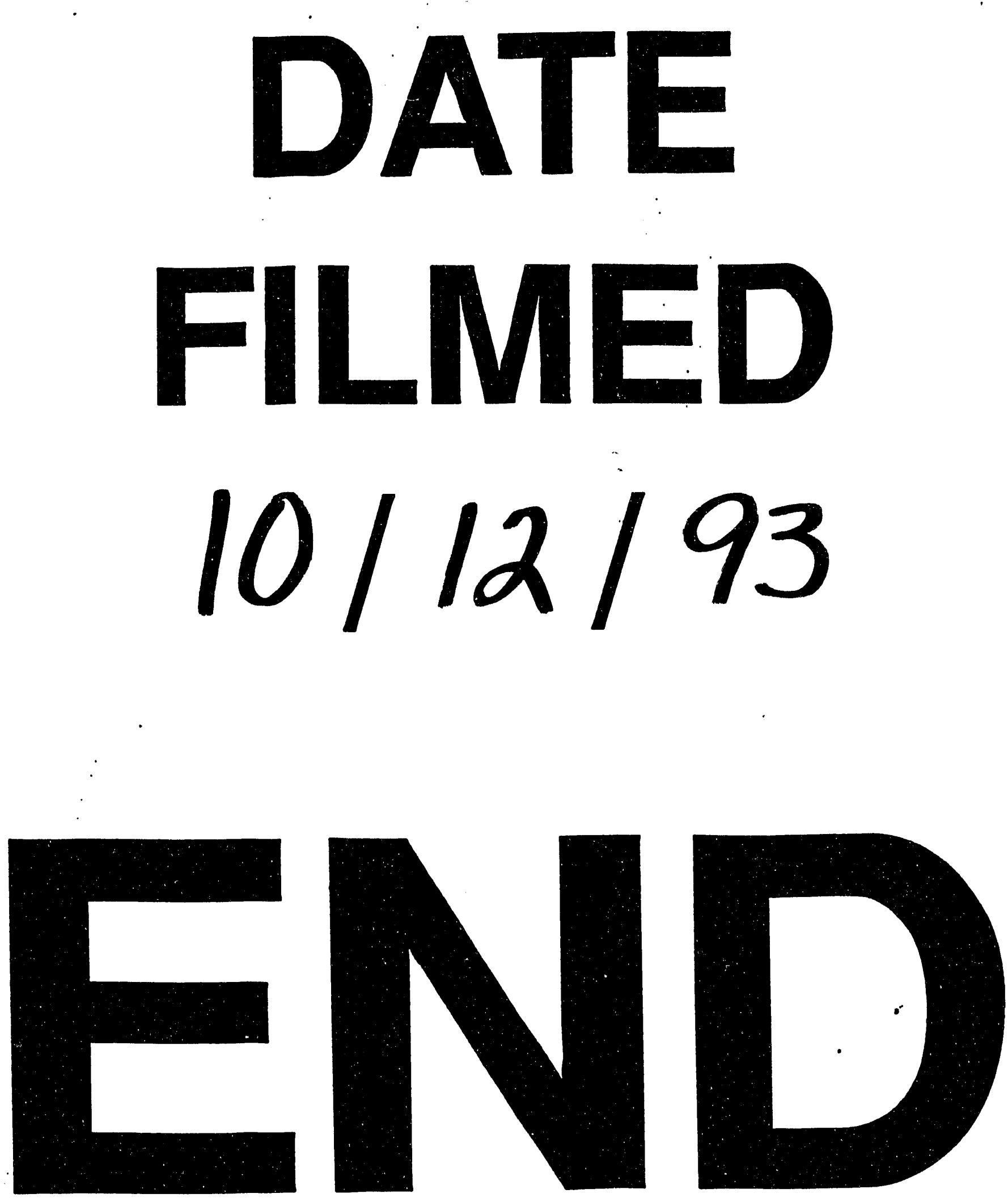
